OPEN ACCESS

Edited by:

Gautam Sethi,

National University of Singapore,

Singapore

Reviewed by:

Dhiraj Kumar,

National Centre for Cell Science, India

Subash Gupta

Banaras Hindu University, India

*Correspondence:

Ondrej Slaby

ondrej.slaby@ceitec.muni.cz

Specialty section:

This article was submitted to

Cancer Molecular Targets and

Therapeutics,

a section of the journal

Frontiers in Pharmacology

Received: 28 June 2016 Accepted: 06 September 2016

Published: 27 September 2016

Citation:

Merhautova J, Demlova R and Slaby O (2016) MicroRNA-Based

Therapy in Animal Models of Selected Gastrointestinal Cancers.

Front. Pharmacol. 7:329

doi: 10.3389/fphar.2016.00329

\section{MicroRNA-Based Therapy in Animal Models of Selected Gastrointestinal Cancers}

\author{
Jana Merhautova ${ }^{1,2}$, Regina Demlova ${ }^{2}$ and Ondrej Slaby ${ }^{1,3 *}$ \\ ${ }^{1}$ Molecular Oncology II - Solid Cancer, Central European Institute of Technology, Masaryk University, Brno, Czech Republic, \\ ${ }^{2}$ Department of Pharmacology, Faculty of Medicine, Masaryk University, Brno, Czech Republic, ${ }^{3}$ Masaryk Memorial Cancer \\ Institute, Brno, Czech Republic
}

Gastrointestinal cancer accounts for the 20 most frequent cancer diseases worldwide and there is a constant urge to bring new therapeutics with new mechanism of action into the clinical practice. Quantity of in vitro and in vivo evidences indicate, that exogenous change in pathologically imbalanced microRNAs (miRNAs) is capable of transforming the cancer cell phenotype. This review analyzed preclinical miRNA-based therapy attempts in animal models of gastric, pancreatic, gallbladder, and colorectal cancer. From more than 400 original articles, 26 was found to assess the effect of miRNA mimics, precursors, expression vectors, or inhibitors administered locally or systemically being an approach with relatively high translational potential. We have focused on mapping available information on animal model used (animal strain, cell line, xenograft method), pharmacological aspects (oligonucleotide chemistry, delivery system, posology, route of administration) and toxicology assessments. We also summarize findings in the field pharmacokinetics and toxicity of miRNA-based therapy.

\footnotetext{
Keywords: microRNA, gastric cancer, pancreatic cancer, gallbladder cancer, colorectal cancer, animal model, mice, preclinical testing
}

\section{INTRODUCTION}

Research in the field of non-coding nucleic acids has advanced extensively in the last 15 years. It is now well known, that dysregulation of miRNAs, powerful regulators of gene expression, is associated with many diseases. MiRNAs are investigated thoroughly in cancer biology and oncology and the number of published articles is growing (Figure 1). Last 10 years brought us an immense amount of information about the roles of miRNAs in cancer cell pathophysiology. All described hallmarks of cancer (Hanahan and Weinberg, 2011) are in relation with some miRNA imbalance (Ruan et al., 2009). Attempts to therapeutically interfere with miRNAs levels in pathologic cells are moving forward to preclinical and clinical phases of new therapies development. Although there are severe limitations and barriers facing miRNA-based therapy, more and more studies are performed with auspicious results.

The purpose of this review is to analyze preclinical studies carried out on animal models of selected gastrointestinal cancer (gastric, pancreatic, gallbladder, and colorectal). We have focused primarily on pharmacological aspects of miRNA-based therapy with the emphasis on delivery systems, and also on the type of animal model, and on toxicity assessments. Eventually, we summarize important findings in the field pharmacokinetics and toxicity of miRNA-based therapy to make the picture comprehensive. 


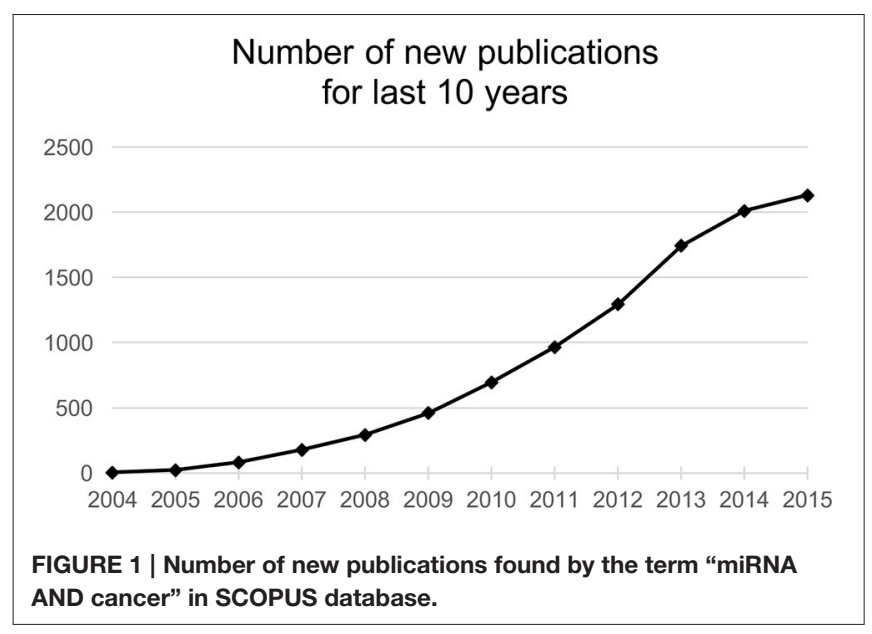

\section{The Biogenesis of Endogenous miRNAs}

MiRNAs are endogenous small $(\sim 22$ nt $)$ single-stranded non-coding RNAs. Their main role in the cell lies in post-transcriptional attenuation of mRNA translation. The biosynthesis of miRNAs begins in the nucleus. Long double-stranded transcripts (pri-miRNAs) are formed by RNA-polymerases II and III. Pri-miRNAs are cleaved by the ribonuclease Drosha and DGCR8 protein to form pre-miRNAs, double-stranded chains $\sim 70$ nt long. Pre-miRNAs are then transported from the nucleus to the cytoplasm via Exportin-5 protein. In the cytoplasm, mature miRNAs are created through the interaction with endonuclease Dicer and TRBP protein. Double-stranded formation is rearranged, the guide strand forms a complex with Argonaut and other proteins forming miRISC complex, and plays an active role in the gene expression attenuation. The other strand, called passenger strand, is usually degraded in the cytoplasm, or persists and may exert its own biological activity. For detailed information on miRNA biogenesis see a recent review by Romero-Cordoba et al. (2014).

There are also number of proofs of mature miRNAs' presence and activities in the nucleus (Hwang et al., 2007; Park et al., 2010; Jeffries et al., 2011; Li et al., 2013). It seems that these miRNAs could transfer from cytoplasm to nucleus and nucleolus via Exportin-1 and Importin-8 (Li et al., 2013; Wei et al., 2014) and influence expression of other miRNAs, or of its own (Tang et al., 2012; Zisoulis et al., 2012; Wei et al., 2014).

\section{Mechanism of Action}

MiRNAs bind mainly to the $3^{\prime}$-untranslated region of mRNA ( $3^{\prime}$-UTR), although there are several evidences that miRNAs could bind to the $5^{\prime}$-UTR, or to the coding sequence itself (Ott et al., 2011; Gu et al., 2014). In the case of imperfect matching, the duplex mRNA:miRNA is not translated, or it is translated incompletely and the polypeptide chain is subsequently degraded. Binding of miRNA to mRNA target also activates deadenylation of $3^{\prime}$-poly(A) end of mRNA through deadenylases, which is a first step of mRNA destabilization and later degradation by $3^{\prime}$ - and $5^{\prime}$-exonucleases (Figure 2). Perfect matching leads to direct cleavage of the target mRNA. Imperfect matching is more common in animal cells, while perfect matching is typical for plant cells (Axtell et al., 2011). The binding specificity is ensured by the seed sequence of miRNA, which contains 6-8 nt and which is very often conservative through the species (Hogg and Harries, 2014). One miRNA can regulate many different genes, and more than $50 \%$ of all genes are suggested to be regulated by miRNAs. Thus, miRNA network affect most of cellular processes from the basic metabolic maintenance, through differentiation, cell division and proliferation, to the death (Calin and Croce, 2006; Esquela-Kerscher and Slack, 2006; Garzon et al., 2006; Zhang et al., 2013).

In cancer tissues, a lot of changes in miRNA levels could be found. MiRNAs decreased in cancer cells are termed tumor suppressors and reversely, oncogenic miRNAs are those abundant in cancer tissue. There have already been signs of miRNAs that function both as tumor suppressors, and oncogenes depending on the cell type and state (contextdependent miRNAs) (Esquela-Kerscher and Slack, 2006; Kasinski and Slack, 2011).

To reverse the pathologic imbalance of miRNAs mature miRNAs, miRNA-mimics, precursors, or expression vectors are administered to increase the level of a specific tumorsuppressor miRNA, and miRNA inhibitors are administered to decrease the level of oncogenic miRNA (Figure 3). Promising results of in vitro studies are nowadays being verified on animal models and first preclinical, or even clinical trials are under way.

\section{SEARCH STRATEGY}

Web of Science database was searched for in vivo studies published in the last 5 years (2010-2015) that were focused on colorectal, pancreatic, gallbladder and gastric cancer. Searching formulas miRNA AND vivo AND colorectal/pancreatic/ gallbladder/gastric in article topic (title, abstract and keywords) was used. The search was finished by the end of February 2016. About 430 articles were found and further analyzed to select the specific experimental design: at first, induction of a tumor by transplantation of human or murine tumor cells, or tumor tissue, then followed by the administration of miRNA mimic, precursor, expression vector, or inhibitor. The bulk of the studies found by the searching formula were excluded because of using different methods, e.g., influencing the expression level of miRNA in cancer cells before transplantation into the animal body, or administration of other substances that affect miRNA levels and processes like natural compounds, siRNAs etc. 26 studies included in this review matched the aforementioned criteria.

Both the articles themselves and the supplemental materials were scrutinized with accent on animal model used (animal strain and gender, xenograft method, cancer cell line, or source), pharmacological aspects (oligonucleotide chemistry, delivery system, posology, route of administration), toxicology assessments (methods and findings), and eventually the experimental therapy effect. Some of the information could not be obtained from articles or supplements, as they lacked e.g., animal gender specification. 


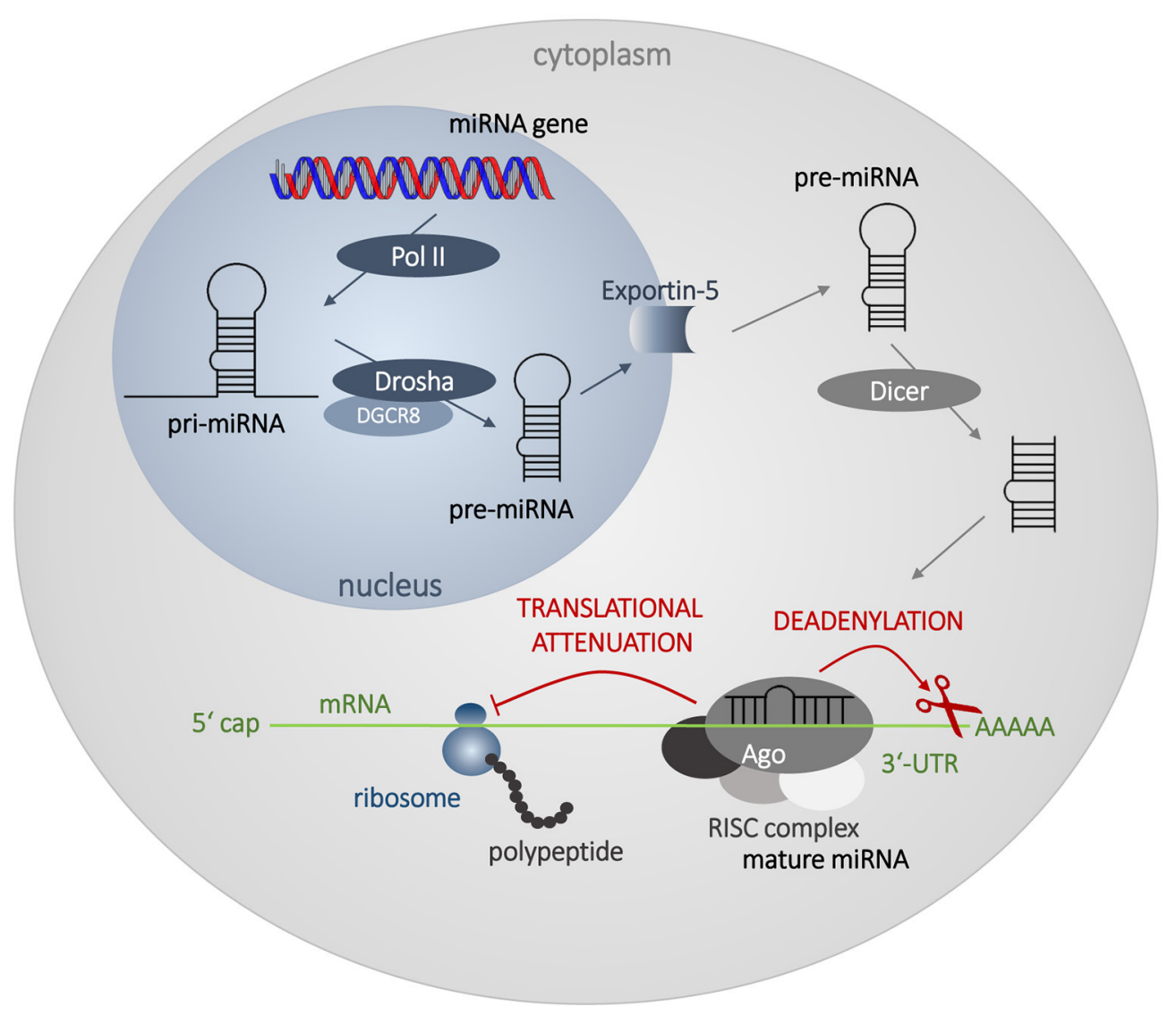

FIGURE 2 | Biosynthesis and mechanism of action of miRNAs. The biosynthesis begins in the nucleus by transcription of miRNA genes by RNA polymerase I| (Pol II). Long transcripts, pri-miRNAs, are cleaved by Drosha and DGCR8 protein creating pre-miRNA with hairpin structure. Exportin 5 transfers pre-miRNA into the cytoplasm, where it is processed by Dicer into miRNA duplex. Mature single-strand miRNA forms RISC complex with Argonaut (Ago) and other proteins and attenuates mRNA translation and leads to the destabilization of mRNA by deadenylation.

\section{OVERVIEW OF THE SELECTED STUDIES}

All selected studies assorted by the organ of cancer cells' origin are summarized in Tables 2-5. Visual summary of therapeutic strategy, type of animal model and routes of administration of miRNA-based therapy is demonstrated in Figures 4-6. We have analyzed 26 studies, 20 of them used the miRNA replacement therapy regimen, and others were miRNA inhibitions. Two studies combined miRNA replacement therapy with chemotherapy, two studies combined miRNA inhibition with either chemotherapy, or immunotherapy. Subcutaneous xenograft model was used in 23 cases, orthotopic xenotransplantation was performed in two experiments, and combination of both was done in one study. In 17 studies, miRNA-based therapeutics were administered locally, i.e., injected intratumorally. Five studies involved systemic administration by tail-vein, or intraperitoneal injection, while four studies combined both routes of administration in a separate substudies, or combined systemic administration of e.g., chemotherapy, with local administration of miRNA-based therapy.
MiRNAs studied in the selected articles were both known tumor suppressors, or oncogenes, and also context-dependent miRNAs whose effect varies according to the type of cancer cell. All of them influence the main hallmarks of cancer such as uncontrolled tumor cell proliferation, impaired process of apoptosis, defects in the control of cell cycle, increased migration and invasivity, or tumor angiogenesis (Table 1). Some miRNAs were tested in combination with cytostatic agents (doxorubicin, gemcitabine, or oxaliplatin) to achieve sensitization of chemotherapy-resistant cells and tumors, e.g., by decreasing the expression of efflux proteins such as ABCB1 (P-glycoprotein). The main result of all in vivo studies was inhibition of tumor xenograft growth, at least in a transient manner. All results and references could be found in Tables 2-5.

Toxicity assessment was part of 11 studies. It was performed at least as animal body weight control but usually was followed by animal behavior observation, histopathology examination of tissue dissections of various organs (brain, heart, liver, lungs, spleen, kidney), or blood biochemistry with regard to liver and kidney functions (blood urea nitrogen, liver enzymes, bilirubin). There were two declared deaths of experimental 


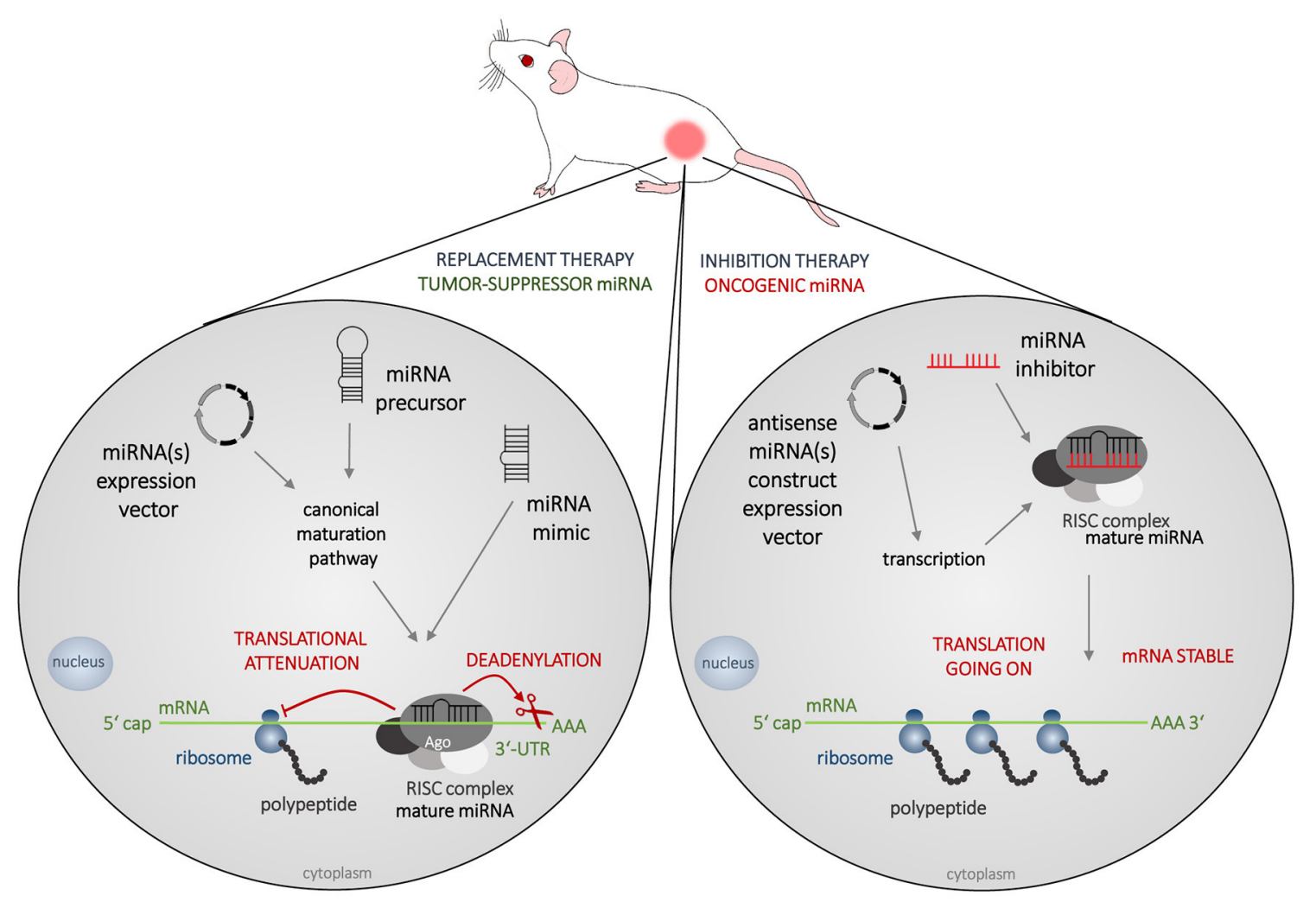

FIGURE 3 | Strategies in miRNA-based therapy. The most frequently used animal model of cancer is immunodeficient mouse bearing a subcutaneous tumor created from cells of human origin. In miRNA-based therapy, two concepts are adopted nowadays, which is the replacement therapy (left) and inhibition therapy (right). Tumor suppressors MiRNAs are decreased in cancer cells and to increase their levels mature miRNAs, miRNA-mimics, precursors, or expression vectors are administered. Oncogenic miRNAs are abundant in cancer tissue and to silence their effects, various types of miRNA inhibitors could be administered.

animals in the selected studies. These mice were administered cholesterol-conjugated oligonucleotide, but both were from the negative control group. The cause of death was not determined (Ye et al., 2013). One study declared slight but statistically significant elevation of blood urea nitrogen in the group of mice treated systemically with mature miRNA conjugated with carbonate apatite nanoparticles (Hiraki et al., 2015). Transient hepatotoxicity was found in mice systemically treated with adenoviral vector Ad-L5-8miR148aT, but the symptoms were milder than those produced by administration of Adwt (Bofill-De Ros et al., 2015). No immune response to the RNA-based treatment was reported in the selected studies, as they used immune deficient strains. Depending on the specific genotype, nude or severe immunodeficient (SCID) mice lack normal cytokine production together with other immune impairments.

The selected studies utilized various types of administered miRNA-based substances and different delivery systems. These issues and their fine tuning are the main points in the successful development of a miRNA-based therapy. Ability to overcome natural barriers that face transferring an oligonucleotide into the cell has to be balanced with the extent of toxicity, as systems with good cell penetration are usually more cytotoxic in a non-specific manner. To bring a complex sight on the development of miRNA-based therapy in gastrointestinal cancer, we gathered relevant information about the type of substances, delivery systems and routes of administration used in the selected 26 studies and we discuss them in detail. The issue of toxicity is described for each delivery system and later on also for the concept of miRNA-based therapy itself.

\section{IMPORTANT ISSUES IN THE FIELD OF MIRNA-BASED THERAPY PRECLINICAL TESTING}

\section{Routes of Administration and Delivery Systems}

MiRNA-based therapeutics in animal studies summarized in this review were administered either systemically, or locally. In systemic delivery, the intravenous (tail-vein) and intraperitoneal injections were used (Figure 6). Local administration was performed as intratumoral injection into the subcutaneous tumors. Delivery systems employed in the presented studies include viral vectors, biocompatible cationic polymers and copolymers, inorganic nanoparticles, atelocollagen, and liposomes. 
TABLE 1 | Examples of studied miRNAs in association with some of the hallmarks of cancer and other cancer cells attributes (I, inhibition strategy; R, replacement strategy).

\begin{tabular}{|c|c|c|c|}
\hline $\begin{array}{l}\text { Cancer cell } \\
\text { attribute }\end{array}$ & Studied miRNA & $\begin{array}{c}\text { Replacement or } \\
\text { inhibition } \\
\text { strategy }\end{array}$ & References \\
\hline \multirow{6}{*}{$\begin{array}{l}\text { Uncontrolled cell } \\
\text { proliferation }\end{array}$} & miR-21 & I & Sicard et al., 2013 \\
\hline & $\mathrm{miR}-27 \mathrm{a}$ & $\mathrm{R}$ & Bao et al., 2014 \\
\hline & miR-33a & $\mathrm{R}$ & Ibrahim et al., 2011 \\
\hline & miR-145 & $\mathrm{R}$ & Ibrahim et al., 2011 \\
\hline & miR-218 & $\mathrm{R}$ & He et al., 2012 \\
\hline & miR-429 & $\mathrm{R}$ & Sun Y. et al., 2014 \\
\hline \multirow{6}{*}{$\begin{array}{l}\text { Impaired } \\
\text { apoptosis }\end{array}$} & let-7 & I & Geng et al., 2011 \\
\hline & miR-20a & I & $\begin{array}{l}\text { Chang et al., 2013; } \\
\text { Wang et al., } 2013\end{array}$ \\
\hline & miR-21 & 1 & $\begin{array}{l}\text { Frampton et al., 2011; } \\
\text { Sicard et al., } 2013\end{array}$ \\
\hline & miR-27a & $\mathrm{R}$ & Bao et al., 2014 \\
\hline & miR-145 & $\mathrm{R}$ & Ibrahim et al., 2011 \\
\hline & miR-4689 & $\mathrm{R}$ & Hiraki et al., 2015 \\
\hline \multirow{4}{*}{$\begin{array}{l}\text { Dysfunction in cell } \\
\text { cycle control }\end{array}$} & $\mathrm{miR}-133 a$ & $\mathrm{R}$ & Dong et al., 2013 \\
\hline & miR-200a & $\mathrm{R}$ & Cong et al., 2013 \\
\hline & miR-218 & $\mathrm{R}$ & He et al., 2012 \\
\hline & miR-1266 & $\mathrm{R}$ & Chen et al., 2014 \\
\hline \multirow[t]{4}{*}{$\begin{array}{l}\text { Cell migration and } \\
\text { invasivity }\end{array}$} & miR-27a & $\mathrm{R} / \mathrm{l}$ & $\begin{array}{l}\text { Frampton et al., 2011; } \\
\text { Bao et al., } 2014\end{array}$ \\
\hline & miR-200a & $\mathrm{R}$ & Cong et al., 2013 \\
\hline & miR-429 & $\mathrm{R}$ & Sun Y. et al., 2014 \\
\hline & miR-1207-5p & $\mathrm{R}$ & Chen et al., 2014 \\
\hline \multirow[t]{2}{*}{ Neoangiogenesis } & miR-27a & 1 & Frampton et al., 2011 \\
\hline & $\mathrm{miR}-27 \mathrm{~b}$ & $\mathrm{R}$ & Ye et al., 2013 \\
\hline \multirow{2}{*}{$\begin{array}{l}\text { Resistance to } \\
\text { cytostatic agents }\end{array}$} & miR-103 & $\mathrm{R}$ & Zhang et al., 2015 \\
\hline & miR-107 & $\mathrm{R}$ & Zhang et al., 2015 \\
\hline
\end{tabular}

\section{Viral Vectors}

Viral vectors could be administered both locally, and systemically and they include lentiviruses, adenoviruses, and adeno-associated viruses (Chen et al., 2015). Viral delivery of antisense construct expression vectors was used to inhibit miR-21 and miR-148a in animal models of pancreatic cancer (Bao et al., 2014; Bofill-De Ros et al., 2015), while expression vector for miR-1266/1207$5 p$ was examined in replacement therapy in gastric carcinoma (Chen et al., 2014). Viruses are able to effectively deliver miRNA therapeutics (precursors, mimics, genes, or inhibitors) into the tumor cell, but their use could be associated with the risk of insertional mutagenesis, gain of replication competency of viral particles, or immune activation. Nucleic acid of adenoviruses (dsDNA viruses) and adeno-associated viruses (ssDNA viruses) usually do not integrate into the host cell genome, while lentiviral (ssRNA viruses) integrates (Soriano et al., 2013; Chen et al., 2015). Adeno-associated viruses are generally less immunogenic, but adenovirus-based delivery system could produce at least transient hepatotoxicity (Broderick and Zamore, 2011; Aslam et al., 2012) as was also observed by Bofill-De Ros et al. in animal model of pancreatic ductal adenocarcinoma (Bofill-De Ros et al., 2015).

\section{Cationic Polymer Polyethylenimine}

In the selected studies, the most frequently used synthetic polymer was polyethylenimine (PEI). It was utilized to deliver mimics or expression vectors of miR-34a, miR-206, and miR217 in animal model of pancreatic cancer, or miR-33a and miR-145 in the model of colorectal carcinoma (Tables 4, 5). PEI is cationic polymer able to produce nanoparticles. It has linear or branched structure and different molecular weight according to the reaction conditions during the synthesis. Due to the positive charge, PEI has high capacity for negatively charged oligonucleotides and nucleic acids which are moreover condensed after complexation with PEI, and thus protected from nucleases. The charge of PEI also facilitate cellular uptake by electrostatic interaction with negatively charged surface molecules (e.g., heparin sulfate proteoglycans), after which the particles enter the cell by endocytosis. PEI is able to disrupt the endosome and release the cargo into the cytoplasm, which grants this method high transfection efficacy. The disruption of endosome is achieved by protonization of PEI and buffering of acidic environment of the vesicle. These processes are followed by osmolarity changes and water intake which leads to the swelling and burst of the endosome (Höbel and Aigner, 2013; Zhang et al., 2013). Better capacity and efficacy is achieved by branched PEI but at the cost of higher nonspecific cytotoxicity. In the presented studies, mostly linear PEI is used, like commercially available transfection reagents ExGen500 ${ }^{\mathrm{TM}}$ (Euromedex, Mundolsheim, France) and in vivojetPEI $^{\mathrm{TM}}$ (Polyplus Transfection, Illkirch, France) assigned for in vivo experiments. Other issues associated with PEI delivery are an aggregation of created nanoparticles, or opsonization in the plasma recognized by phagocytes. PEI with high density of positive charge could also trigger erythrocyte aggregation and thrombosis (Kanasty et al., 2012). PEI particles could be conjugated with various molecules [e.g., polyethylene glycol (PEG), or antibodies] to resolve such difficulties (Malek et al., 2009). PEI is not a biodegradable polymer, thus its toxicity is intensively discussed. It depends strongly on molecular weight and branching (Fischer et al., 1999) and also on the cargo, as it may neutralize the charge of PEI. There are studies describing immune activation in vivo, (Beyerle et al., 2011) hepatotoxicity and lethality in mice (Chollet et al., 2002) and increased apoptosis in vitro (Merkel et al., 2011), and also those that proved no immune response, or hepatotoxicity in mice (Bonnet et al., 2008).

\section{Inorganic Nanoparticles - Iron Oxide, and Carbonate Apatite}

Sun et al. used iron oxide nanoparticles to deliver miR16 and overcome doxorubicin resistance in animal model of gastric adenocarcinoma (Sun Z. et al., 2014). Iron oxide nanoparticles (IONPs) are biocompatible and biodegradable particles with magnetic properties. They are composed of magnetite $\left[\mathrm{Fe}_{3} \mathrm{O}_{4}\right.$, iron (II,III) oxide], or maghemite $\left(\mathrm{Fe}_{2} \mathrm{O}_{3}\right.$, 
ferric oxide) and are usually coated with various other molecules (PEI, PEG, chitosan etc.) to improve their properties (Kievit and Zhang, 2011). IONPs could also serve as theranostics (i.e., substances with both diagnostic and therapeutic purpose). As well as other nanoparticles, IONPs protect nucleic acids from being cleaved by nucleases (Kievit et al., 2009) but could also be opsonized in the plasma and recognized by phagocytes, mainly by the reticuloendothelial system (RES). Non-coated IONPs are distributed in heart, liver, spleen, lungs, kidney, brain, stomach, small intestine, and bone marrow, while the highest concentration are reached in the liver and spleen due to the elimination by RES and macrophages (Wang et al., 2010). IONPs enter the cell by endocytosis and are degraded in the endosomes (Xie et al., 2009). Particles between 10 and $60 \mathrm{~nm}$ are the most effective, as they undergo limited kidney and liver/RES uptake, and are absorbed by tumor cells (Kievit and Zhang, 2011). Cytotoxicity of IONPs coated with PEI occurs in vitro in higher concentration than is needed for sufficient transfection (Lellouche et al., 2015). The administration in vivo could increase blood iron and intracellularly increase oxidative stress (Mahmoudi et al., 2011). Non-coated particles could produce hepatotoxicity, and lung or kidney damage (Hanini et al., 2011).

Study of Hiraki et al. describes utilization of different inorganic nanomaterial, carbonate apatite nanoparticles. They used these particles as a delivery system for mature miR4689 in animal model of colorectal adenocarcinoma (Hiraki et al., 2015). Carbonate apatite $\left[\mathrm{Ca}_{10}\left(\mathrm{PO}_{4}\right)_{6-\mathrm{X}}\left(\mathrm{CO}_{3}\right)_{\mathrm{X}}(\mathrm{OH})_{2}\right]$ is composed of calcium cations and phosphate and carbonate anions in defined ratios. It was firstly described as a transfection reagent and a delivery system for plasmid DNA by Chowdhury et al. (2006). Nanoparticles of carbonate apatite are stable in plasma $(\mathrm{pH}=7.4)$, protect nucleic acids from nuclease cleavage, but in acidic environment of endosomes, they are quickly degraded. Their cargo is then released and could probably escape from endosomes, as high effectivity of this transfection method was proved for DNA (Wu et al., 2015) and RNA (Hossain et al., 2010). In mice, these nanoparticles are accumulated in tumor probably due to the EPR effect (discussed below), but slight accumulation was found also in the liver (Wu et al., 2015). As this method arose from calcium phosphate co-precipitation, which is known to produce certain level of cytotoxicity in vitro, adverse effects in animals were inquired. In mice, $\mathrm{Wu}$ et al. declared no mortality, weight loss, or histological damage in liver, kidney, and spleen after administration of common dose, and also after 2.5 and 5-fold higher doses. They also do not observed any urinary calculi in a mouse model of repeated administration. The team advanced to the evaluation of the delivery system on monkeys (macaques Macaca fascicularis, formerly M. cynomolgus). Monkeys received repeated i.v. infusions during a movement restraint. Equivocal results were obtained, as some animals had reversible increase in AST, ALT, LDH, and CPK enzymes, but from further analyses of isoenzymes, authors suggested that these increments might arise from the stress associated with body restriction rather from heart or liver damage (Wu et al., 2015).

\section{Atelocollagen}

For direct intratumoral treatment, atelocollagen was used in the study of Frampton et al. in pancreatic ductal adenocarcinoma to deliver miR-21, miR-23a, and miR-27a (Frampton et al., 2011). Atelocollagen is a biocompatible and biodegradable polymer. It was developed and tested in vivo for gene (plasmid) delivery with controlled release by Ochiya et al. (Ochiya et al., 1999; Hao et al., 2016). Atelocollagen is prepared from collagen extracted from bovine dermis. Natural collagen contains specific amino acid sequences on both C- and N-terminus ("telopeptides"), which are highly immunogenic. By digestion with pepsin, these telopeptides are cleaved. The polymer is liquid at low temperatures, but solidifies at temperatures above $30^{\circ} \mathrm{C}$ (Ochiya et al., 2001; Komatsu et al., 2016). After intramuscular injection of plasmid DNA in complex with glucose and atelocollagen in mice, the transfection was efficient and last more than 60 days. No apparent toxicity, or hematologic changes were observed in this study, (Ochiya et al., 1999) as well as Frampton et al. described neither changes in mice body weight, nor serious adverse effects (Frampton et al., 2011).

\section{Cationic Lipids and Liposomes}

For intratumoral administration, several studies used lipidbased transfection reagent Lipofectamine 2000 (Thermo Fisher Scientific, Waltham, USA) designed originally for in vitro experiments, e.g., Dong et al. in animal model of colorectal adenocarcinoma to deliver miR-133a (Dong et al., 2013). Pramanik et al. utilized DOTAP ( $N$-[1-(2,3-dioleoyloxy)propyl]$\mathrm{N}, \mathrm{N}, \mathrm{N}$-trimethylammonium methyl-sulfate) with co-lipids formula to deliver plasmid expression vector of miR-34a, and miR-143/145 cluster systemically in animal model of pancreatic ductal adenocarcinoma (Pramanik et al., 2011). Both delivery systems are composed of cationic lipids that form liposomes, vesicles with lipophilic bilayer and aqueous core able to encapsulate hydrophilic molecules (Mallick and Choi, 2014). By electrostatic interaction, cationic lipids have increased capacity for negatively charged nucleic acids (Xue et al., 2015). They enter the cells by endocytosis and are able to destabilize and breach endosomal membrane by interaction with its phospholipids (Zelphati and Szoka, 1996). Cationic lipids exert detergent effect on lipid membranes and interact also with enzymes, thus could irritate cells, decrease proliferation, alter gene expression, and even trigger cell lysis (Wu et al., 2001). They share the same advantages and disadvantages that account for positive charge as cationic polymers. They form aggregates with plasma proteins leading to RES elimination and accumulation in spleen and liver (Nchinda et al., 2002; Zhang et al., 2012). With decrease of positive charge, RNA encapsulation and transfection efficacy is decreasing. PEGylation increases blood circulation time of liposomes, (Pathak et al., 2011; Suk et al., 2016) but could lead to the formation of anti-PEG IgM antibodies (Ishida et al., 2006). Liposomes are generally less immunogenic than cationic polymers. But after processing of liposomes, some RNA molecules might remain on the surface of a particle. In the studies using siRNA, these residues lead to the significant immune activation (Xue et al., 2015). Inflammatory response in the liver followed by hepatotoxicity and with higher doses 


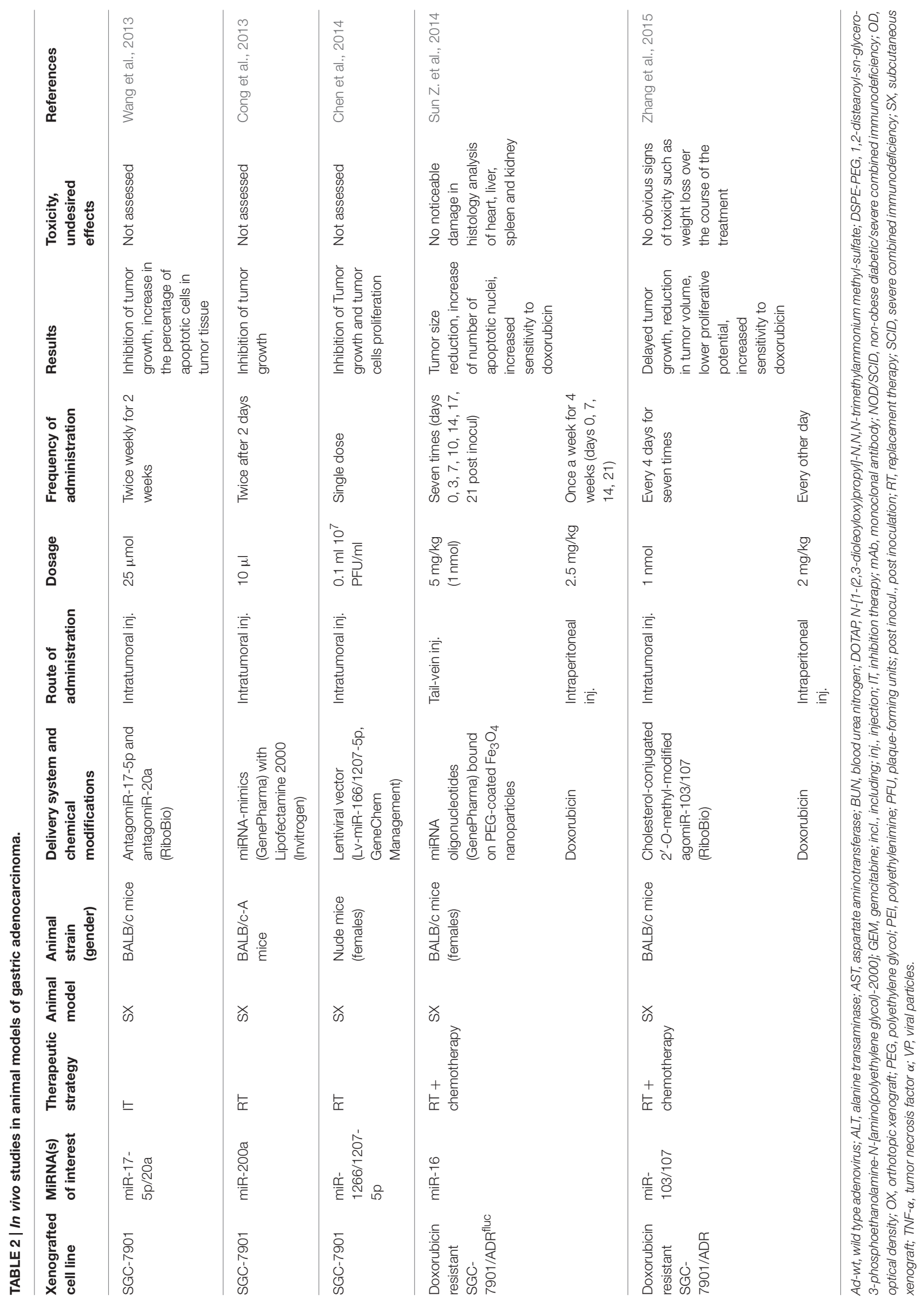


even lethality was described (Tan and Huang, 2002; Zhang et al., 2005).

\section{Pharmacokinetics of Therapeutic Oligonucleotides Chemistry, Physico-Chemical Properties, and Absorption}

Pharmacokinetics of therapeutically administered oligonucleotides is strongly driven by their physico-chemical properties. Generally, these properties are not sequence-specific in qualitative point of view, but can be quantitatively different from sequence to sequence, and could differ also between chemistries. Native oligonucleotides are small, negatively charged molecules, which means that the transfer through lipophilic membranes necessary for the absorption into systemic blood circulation and also later into the intracellular space is quite problematic.

The most common change in oligonucleotide chemistry is the replacement of phosphodiester bond with phosphorothioate bond in the backbone. This change goes usually hand in hand with chemical modification of the $2^{\prime}$ functional group on ribose in the nucleotide ( $2^{\prime}$-hydroxyl could be substituted e.g., to 2'-O-methyl, 2'-O-methoxyethyl, or 2'-fluoro group), and conjugation with cholesterol. These modifications either increase the stability of oligonucleotides modifying their susceptibility to RNAse cleavage (phosphorothioate bonds, $2^{\prime}$-O-modifications), or increase cellular uptake of the molecule (cholesterol conjugation). Cholesterol-conjugated 2'-O-methyl/methoxyethyl-modified oligonucleotides are sometimes termed "agomiRs" or "antagomiRs" depending on their mechanism of action, and they were utilized in some of the studies focused on gastrointestinal cancer presented in this article (Chang et al., 2013; Wang et al., 2013; Zhang et al., 2015; Zou et al., 2015). Modification on $2^{\prime}$ position could also change the affinity of oligonucleotides to plasma proteins which has a high impact on pharmacokinetics, most importantly on distribution and excretion (Crooke, 2007).

Another possibility to change oligonucleotide structure is chemical modification of the ribose forming a $2^{\prime}, 4^{\prime}$-bicyclic structure, which is termed locked nucleic acid (LNA) (Kumar et al., 1998). The most common type of LNA is oligonucleotide with one or more $2^{\prime}-O-4^{\prime}$-methylene- $\beta$ - $D$-ribosyl structure. This bicyclic bridge locks ribose in one of its conformation increasing binding affinity and decrease the susceptibility to nuclease cleavage (Braasch and Corey, 2001).

Various chemical modifications in the oligonucleotide structure are now available owing to the development of commercially available miRNA mimics. According to the information provided by manufacturers, miRNA mimics should possess higher affinity to miRISC and thus to the mRNA of interest. MiRNA-mimics should have no off-target biological activities due to the passenger strand, and should exert higher effect than native mature miRNAs. The chemistry modifications differ between passenger and guide strand, and the molecules could also be triple-stranded (e.g., Exiqon, Vedbaek, Denmark). Detailed information about the specific chemistry of the 
miRNA mimic are usually not released. Some evidences were published last year, that bring the commercially available miRNA mimics into focus because of non-specific dampening effect on overall gene expression, accumulation of non-endogenous high molecular weight RNA species and unintentional passenger strand loading into the RISC discovered after transient transfection of human cell lines. Søkilde et al. describe variations even between batches of a commercially available miRNA mimic obtained from one manufacturer (Søkilde et al., 2015). The authors emphasize the issue of a proper dosage of miRNA mimic and its optimization, and suggest to prefer viral and genetic approaches, as the created transcripts follow the physiological biosynthesis pathway and their mechanism of action could be considered as the very same as endogenous miRNAs (Jin et al., 2015).

Undesirable physico-chemical properties of oligonucleotides could be attenuated by delivery systems mentioned before, which subsequently influence pharmacokinetic processes of miRNAbased therapeutics.

\section{Distribution, Protein Binding, and Tissue Accumulation}

After being absorbed or injected into systemic circulation, charged molecules of oligonucleotides bind to various plasma proteins, above all on albumin and $\alpha_{2}$-macroglobulin (Cheng et al., 2013). The binding and the distribution is nonlinear, saturable, changes slightly with length and sequence of oligonucleotides and is different in rodents and in human. Distribution to the tissues is very quick and prevails over metabolic degradation (Levin, 1999). Naked oligonucleotides accumulate in the liver, kidneys, spleen, bone marrow and lymphatic nodes, while they do not cross the blood-brain barrier, placental barrier and they are not present in testes.

In the treatment of cancer, accumulation of a drug in the tumor tissue or in the metastasis site is a desirable state. MiRNA-based therapeutics could achieve this due to enhanced permeability and retention (EPR) effect of a tumor. Enhanced permeability of new vessels and relative lack of lymphatic vessels in the tumor site was firstly described by Matsumura and Maeda (1986). Charge-neutral small particles complexed or loaded with miRNA-based therapeutics have enhanced extravasation and could accumulate in the tumor. Metastatic sites are generally less accessible, as their EPR effect is not so significant (Maeda, 2015).

According to the technology of the delivery system used, miRNA-based therapeutic could accumulate also extratumorally in various tissues. All cells capable of phagocytosis accumulate naked oligonucleotides, liposomes, or nanoparticles, e.g., RES cells present in the liver (Kupfer cells) and in the circulation, tissue monocytes and macrophages, and proximal tubular cells (Chen et al., 2015). In this case, the delivery system alone as a protection could be insufficient, because in plasma, these particles get coated by proteins recognized by the RES. The most common defense against RES is PEGylation, binding of polyethylene glycol substituents on the surface of a nanoparticle or liposome, which prevent binding of opsonization proteins and became very common. Contrarily, the excess of PEG on the surface of a delivery system particle could diminish cellular uptake, therefore the process of PEGylation should be optimized (Seto, 2010).

Oligonucleotides, liposomes and polymer-based nanocarriers enter the cell by active mechanism, endocytosis. Escape from endosomes is desired to reach the interaction of miRNA with mRNA, however, this is another obstacle in miRNA-based therapy. Some of the carriers could enhance endosomal escape by steric or osmotic effects. $\mathrm{pH}$ sensitive molecules could change structure in relatively acidic environment due to electrostatic interactions, which is leading to the mechanical disruption of the vesicle and release of miRNA into cytoplasm (Ju et al., 2014). Other molecules are accepting $\mathrm{H}^{+}$(proton sponges) and by alteration of ion homeostasis cause swelling and burst of the endosome (Akinc et al., 2005; Chen et al., 2015).

\section{Metabolism of miRNA-Based Therapeutics}

Ubiquitous nucleases begin to degrade oligonucleotides shortly after administration. According to the chemistry changes, free oligonucleotides are metabolized by $3^{\prime}$ - and $5^{\prime}$-exonucleases or by endonucleases, and the rate of metabolism depends on the chemical modifications. Endonuclease cleavage is slower and takes place only when $3^{\prime}$ and $5^{\prime}$ end of oligonucleotide is protected by methoxyethyl-modified nucleotides. As was mentioned before, modifications on $2^{\prime}$-hydroxyl on ribose or structural changes in the backbone such as LNA structure can decrease the affinity of nucleases to cleave miRNAbased therapeutics. Also the complexes of oligonucleotides with nanoparticles or liposomes have modified susceptibility to nuclease cleavage.

The metabolites of nuclease cleavage are weakly bound to the plasma proteins and therefore are rapidly excreted in urine. Oligonucleotides do not undergo liver oxidation by cytochrome P450, or conjugation processes (Levin, 1999; Crooke, 2007).

\section{Excretion}

Oligonucleotides not bound to proteins are excreted in the urine, while binding to plasma proteins, or other delivery systems like liposomes and nanoparticles of specific parameters (e.g., hydrodynamic diameter up to $5-6 \mathrm{~nm}$ ) results in protection from being urinary excreted (Crooke, 2007; Cheng et al., 2013). As oligonucleotides accumulate also in the liver, they could be excreted by both these organs. About $10 \%$ of the administered dose of naked oligonucleotides, and $80 \%$ of the metabolites are urinary excreted. The remaining are excreted by faeces, or endure bound to the tissue, or inside the cells. The elimination halflife of oligonucleotides is 1-30 days depending on the type of tissue. This attribute allows designing a therapeutic regimen comfortable for potential patients with one dose administration for a week, 2 weeks, or a month (Crooke, 2007).

\section{Toxicity of miRNA-Based Therapy}

The toxicity of oligonucleotide administration was largely studied in the field of antisense therapy. In miRNA-based therapy specifically, toxicity assessments are not a part every in vivo study and we have very limited information from the first phases of clinical research. For antisense oligonucleotides not targeted to miRNAs, there are evidences from rodent and non-rodent 


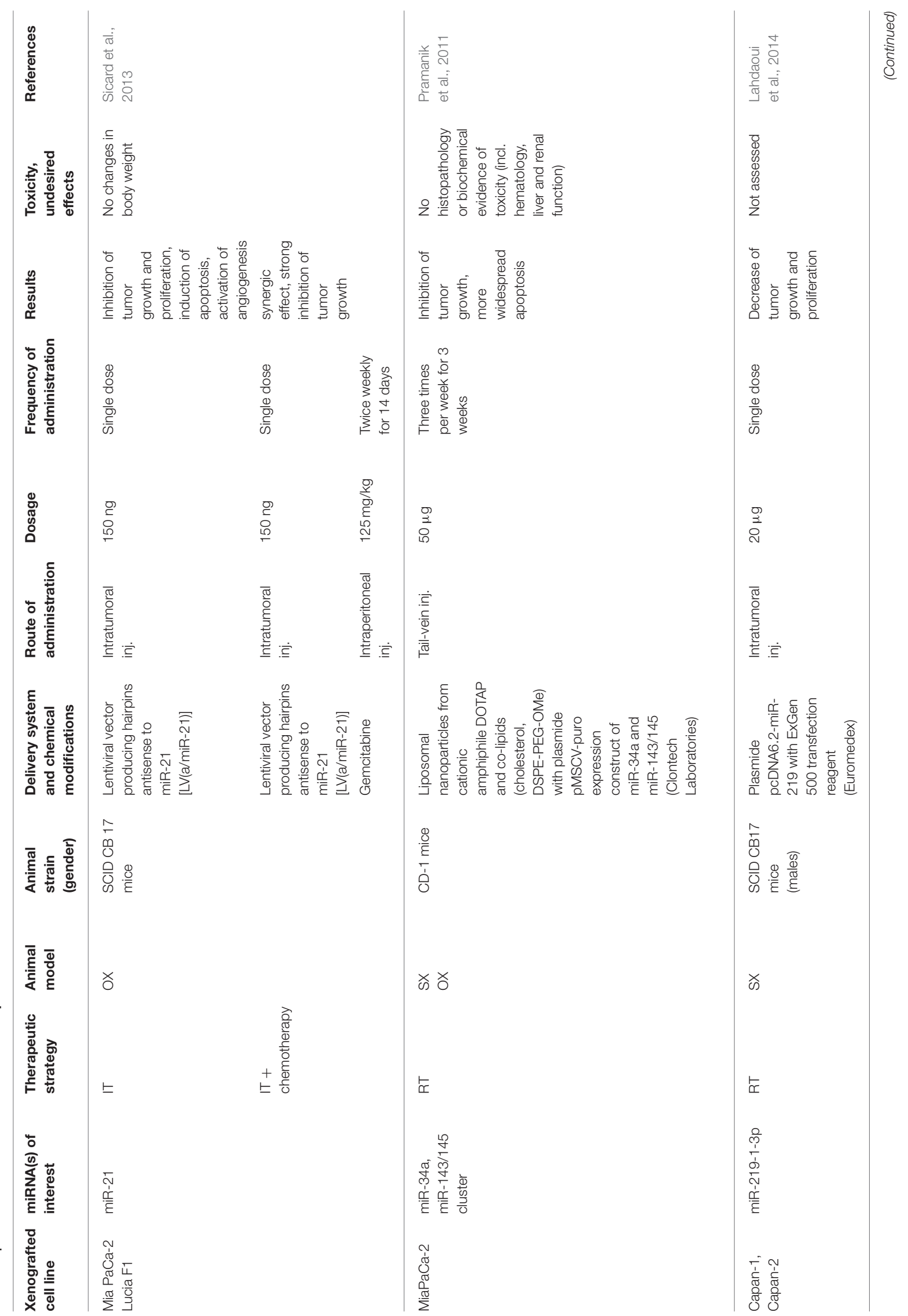




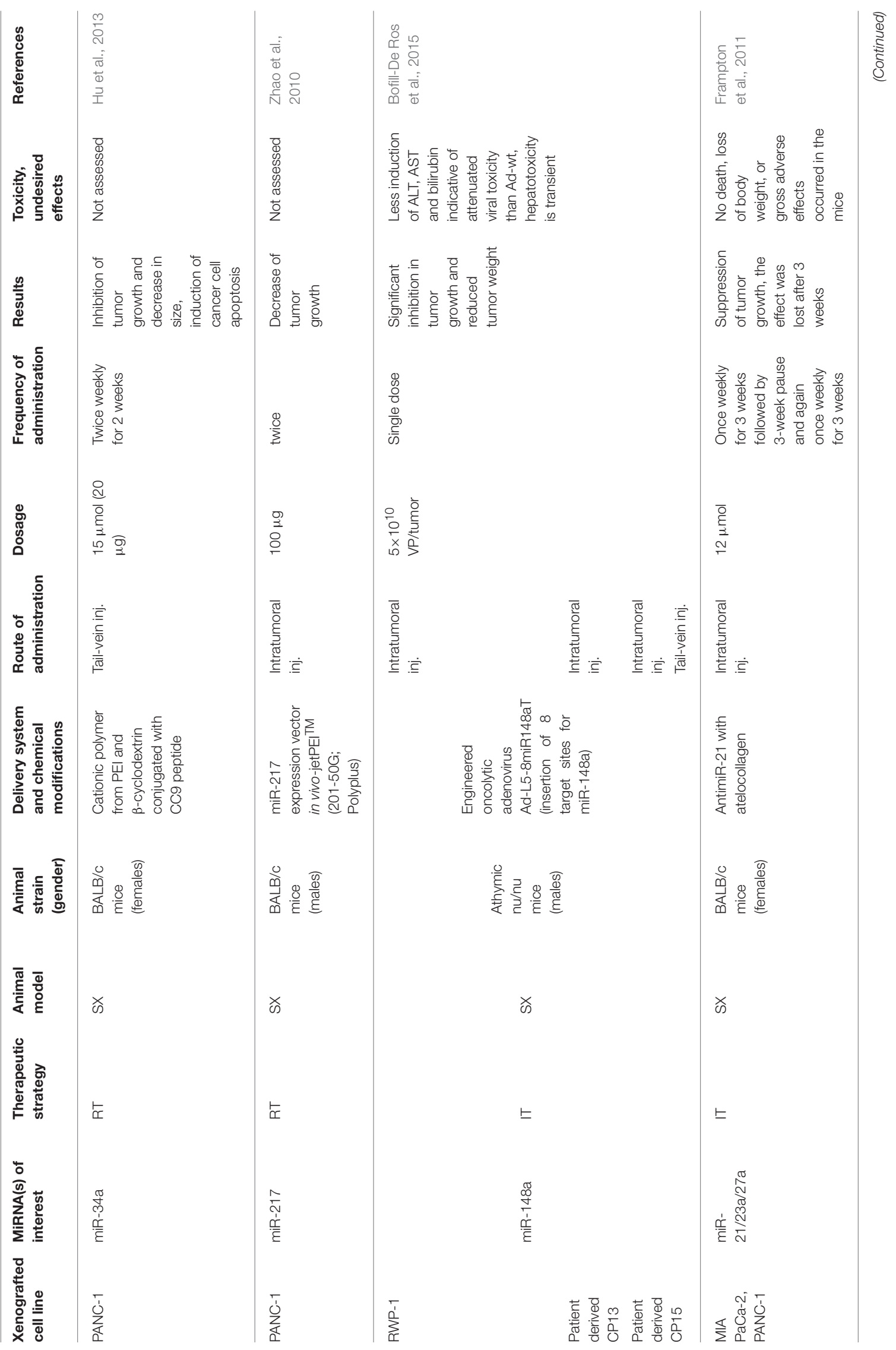




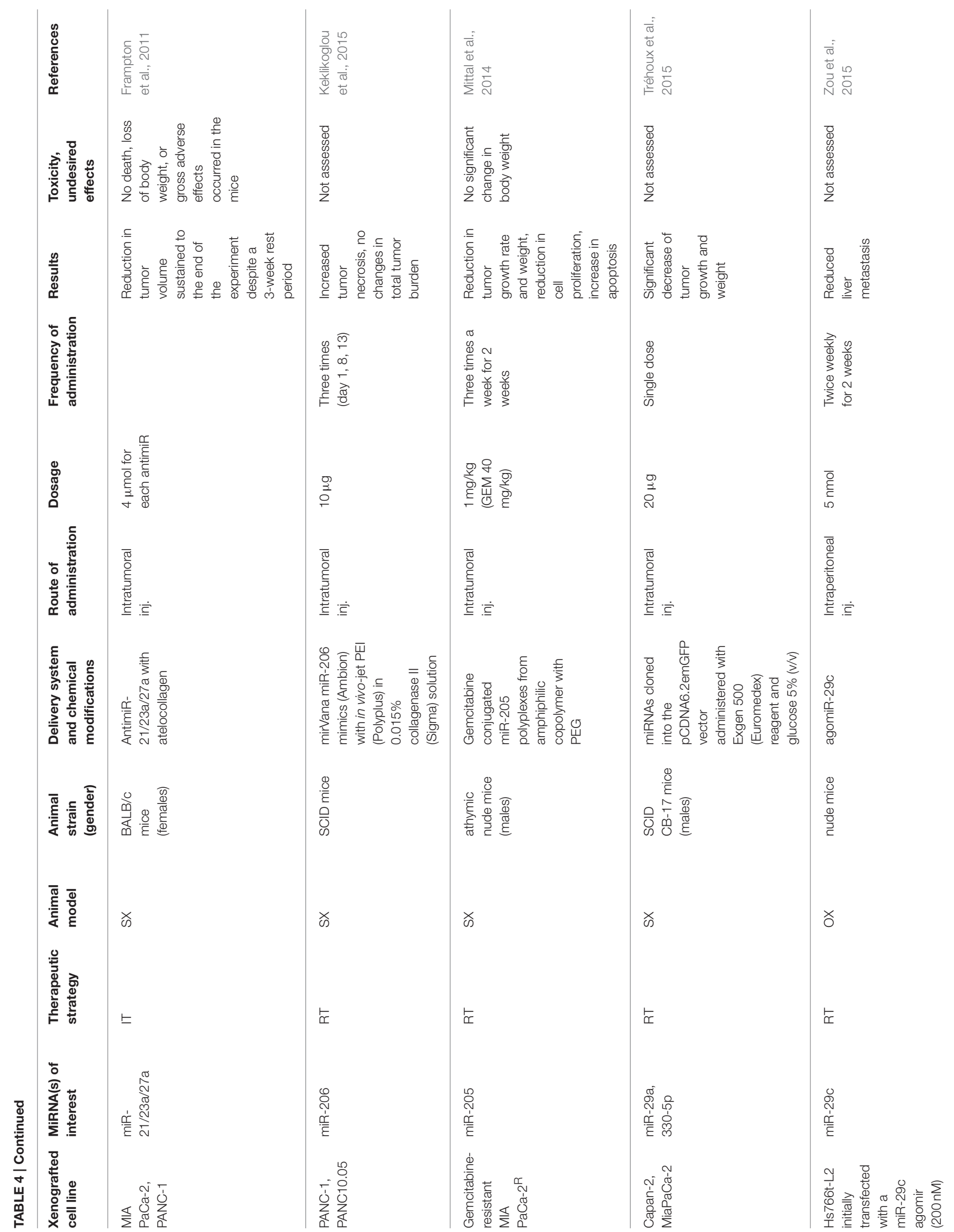




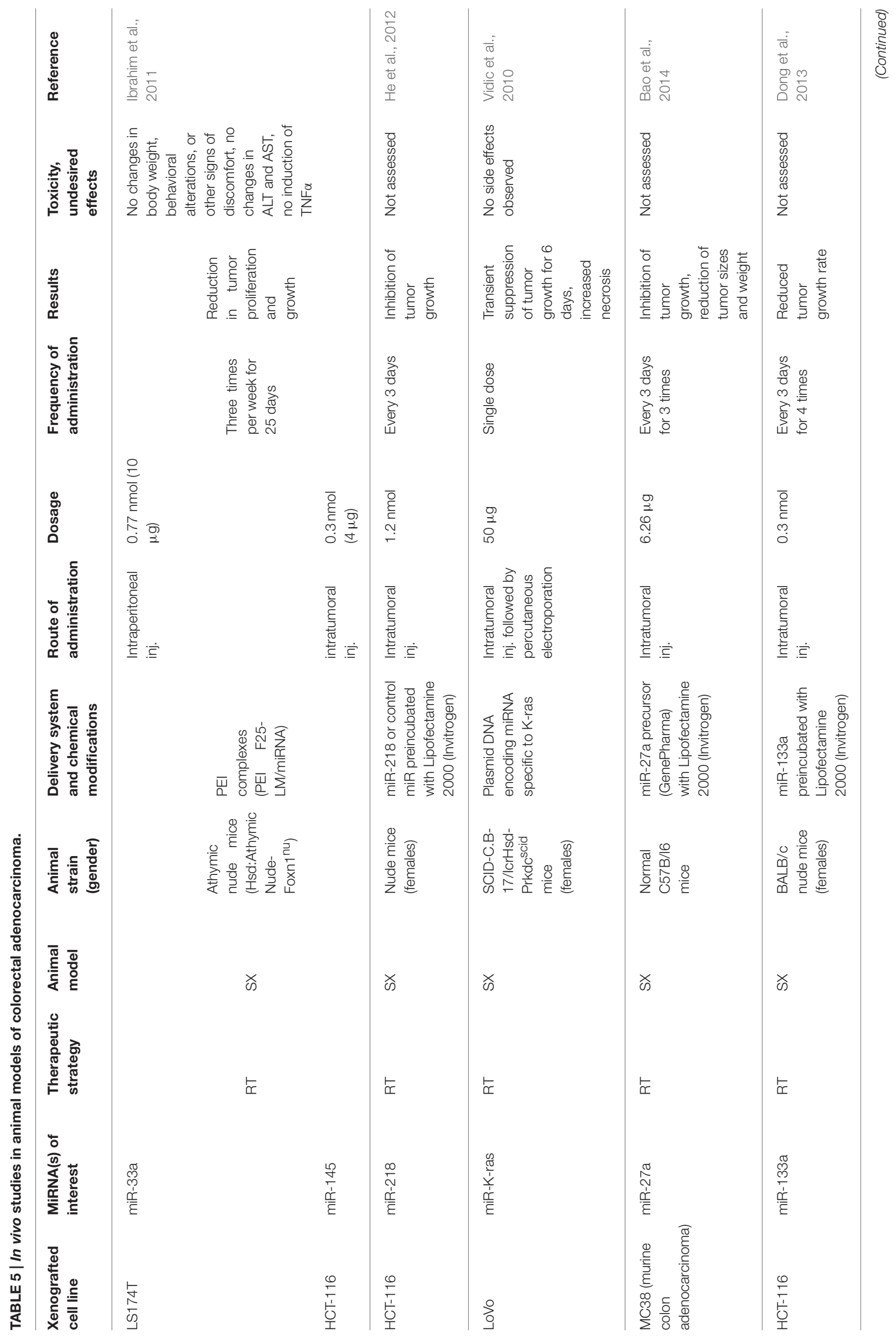




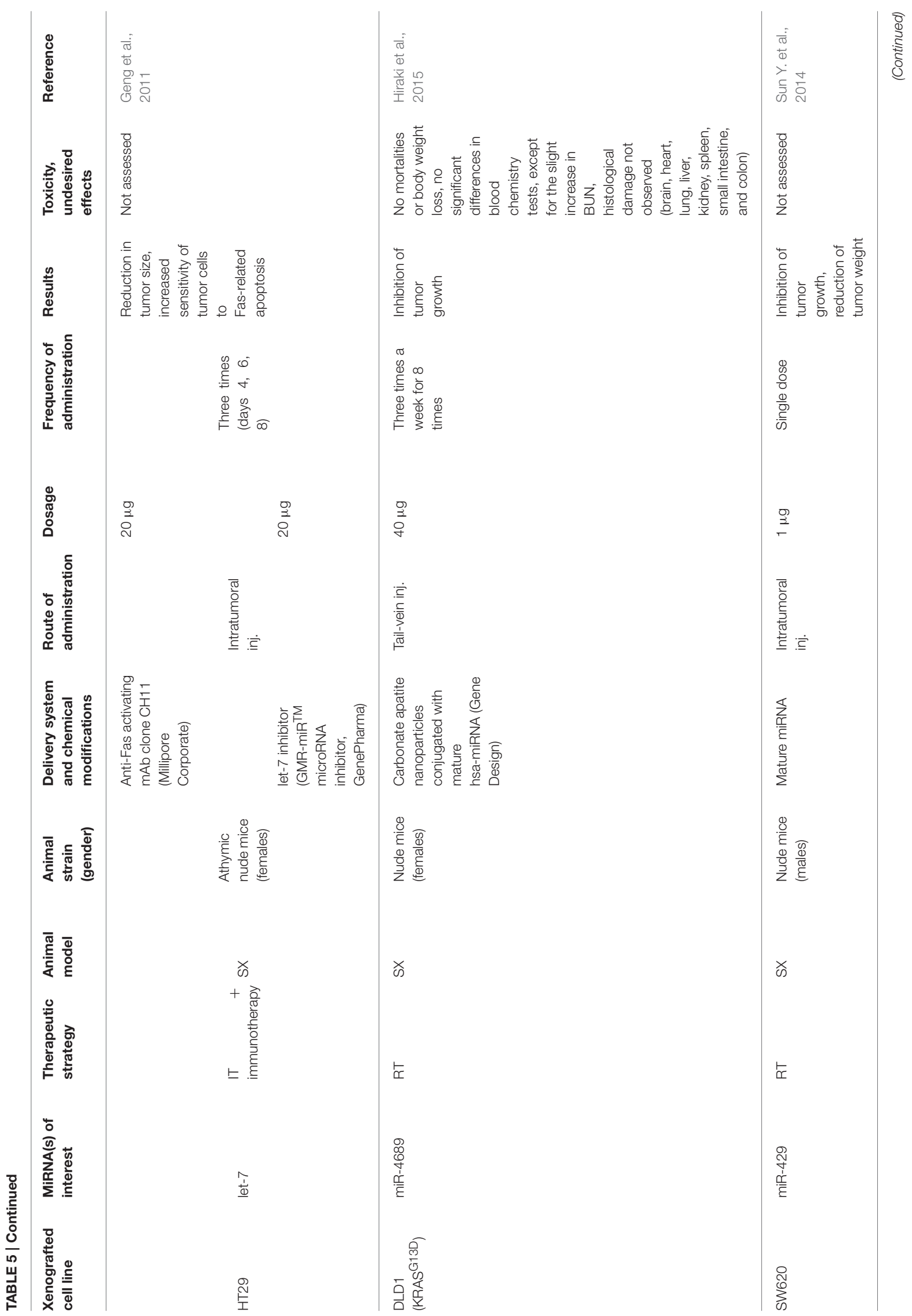



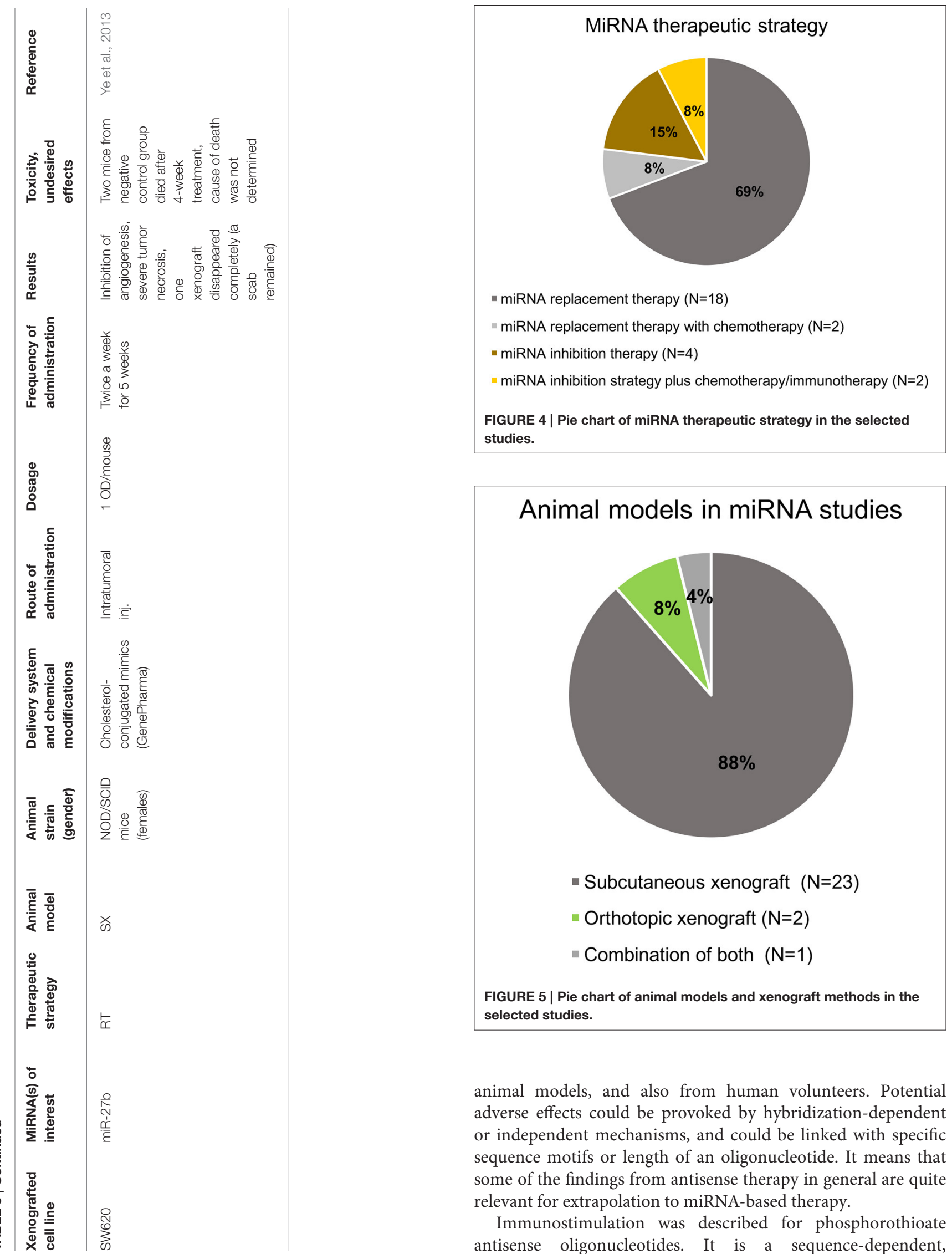

\section{Animal models in miRNA studies}

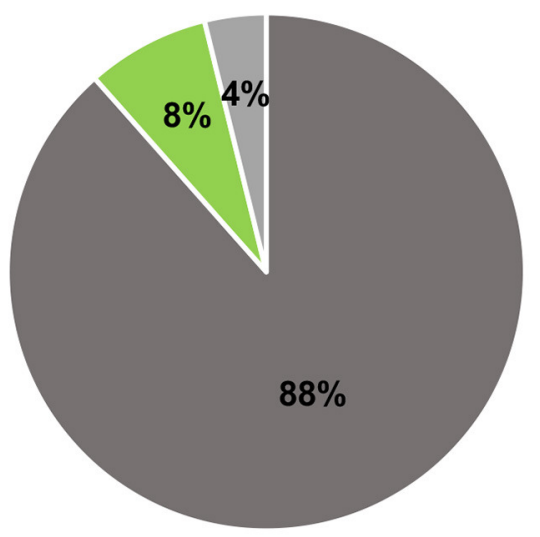

- Subcutaneous xenograft ( $\mathrm{N}=23)$

- Orthotopic xenograft $(\mathrm{N}=2)$

- Combination of both $(\mathrm{N}=1)$

FIGURE 5 | Pie chart of animal models and xenograft methods in the selected studies.

animal models, and also from human volunteers. Potential adverse effects could be provoked by hybridization-dependent or independent mechanisms, and could be linked with specific sequence motifs or length of an oligonucleotide. It means that some of the findings from antisense therapy in general are quite relevant for extrapolation to miRNA-based therapy.

Immunostimulation was described for phosphorothioate antisense oligonucleotides. It is a sequence-dependent, 


\section{Routes of administration of miRNA-based therapy}

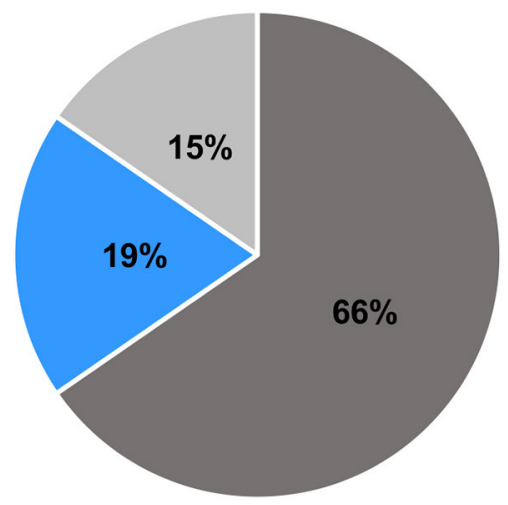

- Local administration (N=17)

- Systemic administration ( $\mathrm{N}=5)$

- Both routes of administration combined $(\mathrm{N}=4)$

FIGURE 6 | Pie chart of routes of administration of miRNA-based therapy in the selected studies.

hybridization-independent process, which leads to the reversible activation of various immune cells (e.g., NK cells, B lymphocytes, mononuclear cells) and increased production of cytokines such as IL-6, IL-12 and interferon $\gamma$ (Levin, 1999; Henry et al., 2002). The main responsible sequence motif is CpG (p stands for phosphodiester bond) or CG palindromic sequences naturally occurring mostly in bacterial genome (Krieg et al., 1995). While unmethylated, this motif is recognized by TLR receptors on immune cells and activates them. The effect is also exerted by oligonucleotides with both phosphorothioate, and phosphodiester bonds in the structure. In rodents, which are more sensitive than primates to this effect, splenomegaly, lymphoid hyperplasia, and multiple organ mononuclear infiltrates were described (Levin, 1999).

Another severe adverse effect relating with immunity is an activation of complement cascade. It prevails over TLR-mediated immune stimulation in primates and its mechanism is probably hybridization/sequence-independent originating from physicochemical properties (polyanionic character) of oligonucleotides. In the study of Henry et al, after reaching a threshold plasma concentration after i.v. infusion, macaques suffered from emesis, ataxia, and facial edema. Hemodynamic changes (fluctuation of blood pressure and tachycardia), changes in blood count (neutropenia followed by neutrophilia), and increase of cytokines mentioned above were described (Henry et al., 2002). When maintaining plasma concentration below the threshold, symptoms were mild or not present, which is in accordance with the results of phase I clinical study with antisense oligonucleotide against intercellular adhesion molecule-1 (ICAM-1) (Glover et al., 1997).
Similar hybridization/sequence-independent mechanism leads also to the influencing of blood coagulation cascade observed in rodents, primates and human (Glover et al., 1997; Henry et al., 1997). Negative charge of oligonucleotides could inhibit intrinsic tenase complex (consisting of factor IXa and VIIIa, which activate factor X), and thus leads to the reversible prolonging of blood clotting and to the increase of activated partial thromboplastin time (aPTT) (Sheehan and Lan, 1998; Levin, 1999).

After administration of relatively high doses of antisense oligonucleotides (above $100 \mathrm{mg} / \mathrm{kg}$ in rodents), histological or laboratory signs of hepatotoxicity and renal toxicity were present in experimental animals. Mostly, immune-mediated cellular infiltrations in liver, multi-focal liver necrosis, and proximal tubules infiltrations were found in rodents. Posology studies indicate that lower doses (below $3 \mathrm{mg} / \mathrm{kg}$ ) do not cause liver and kidney pathologies in monkey and human (Levin, 1999).

Different mechanism could potentially lead to hepatotoxicity, which was proven in rodents (Grimm et al., 2006). By introducing oligonucleotides into the cell, enzymes and other proteins that physiologically deal with these molecules could be saturated, and thus processing of other endogenous RNAs sharing these pathways could be diminished (Bader et al., 2010). This effect was described on mice treated with shRNA (short hairpin RNA) expression vectors. Mice suffered from multifocal liver necrosis followed by ascites, edema, increase of bilirubin and liver enzymes, and decrease of plasma proteins and body weight. Several mice died within 1 month. There were no signs of blood count changes, or increases in cytokine productions. ShRNAs compete of Dicer cleavage and exportin-5 stabilization in cytoplasm with endogenous pre-miRNAs, therefore mature liver miRNAs were found decreased and shRNAs precursors increased in mice with symptoms of hepatotoxicity. As Grimm et al. studied almost 50 distinct shRNAs, they assume that the effect was not sequence related (Grimm et al., 2006). Introducing of miRNA-precursors into the cell could produce the same effect, but the data concerning safety of miRNA-based therapies are limited. Again, proper posology studies are needed.

Another possible mechanism of toxicity is hybridizationdependent. But the toxicity arisen from both binding to the desired mRNAs, and off-target binding is hypothesized to be rare (Bader et al., 2010; van Rooij et al., 2012). MiRNA-mimics and precursors are suggested to be generally better tolerated than antisense therapy (Bader et al., 2010). One miRNA could regulate number of genes, frequently functionally linked in a specific pathway. Targeting more genes in one or more pathologically deregulated pathway could be beneficial. The potential for targeting other genes in different pathways still remains, but influencing of target or off-target genes with impact on cell viability should be revealed during accurate in vitro testing.

\section{MiRNA-BASED THERAPEUTICS IN CLINICAL TRIALS}

Certain chemical modifications of oligonucleotides structure and also several delivery systems for miRNAs have already 
entered clinical phase of drug development. There are no reports of clinical trials of miRNA-based therapies in gastrointestinal malignancies on which we have focused in this reviewcolorectal, pancreatic, gallbladder and gastric cancer. Two experimental miRNA-based therapies are now listed on ClinicalTrials.gov. MiR-34a mimics in an amphoteric liposomal formulation administered i.v. are tested in the phase I in patients with primary liver cancer and advanced or metastatic lung and kidney cancer, melanoma, multiple myeloma and lymphoma (NCT01829971, Adams et al., 2015).

MiR-16 mimic is evaluated in the treatment of malignant pleural mesothelioma also in the phase I (NCT02369198). The therapeutic system used is termed TargomiR and it is based on specific nanoscale delivery system-nonliving bacterial minicells (EnGeneIC Delivery Vehicle, EnGeneIC, New York, USA), and targeted to cancer cells by an anti-EGFR antibody, since EGFR is known to be overexpressed by certain types of cancer. Kao et al. even published some of the preliminary results achieved in the cohort of six patients with malignant pleural mesothelioma describing significant radiologic and metabolic responses indicated by PET-scan (Kao et al., 2015; Quinn et al., 2015).

In non-cancer diseases, the first miRNA-based drug in clinical settings was miravirsen (LNA miR-122 inhibitor) tested as a hepatitis $\mathrm{C}$ treatment. The drug entered clinical trials phase II (NCT02031133, NCT02508090, NCT02452814), but van den Ree has recently referred that the development of miravirsen had been ceased. A more potent miR-122 inhibitor conjugated with $\mathrm{N}$-acetylgalactosamine entered phase II (RG-101, 2016; van der Ree et al., 2016).

Other delivery systems, used in the selected animal studies as carriers for miRNA-based therapeutics, are evaluated in clinical trials for non-miRNA treatment. Future results from these trials may serve also for the development of miRNA-based therapies, as we may obtain e.g., the information about the potential toxicity, or pharmacokinetic aspects of a specific delivery system regardless of its cargo.

Lentiviral vectors are mostly used to transfect cells that are subsequently injected into the patient, e.g., in the treatment of lymphoma (NCT02337985). Adenoviral vectors are evaluated in various solid cancers and are usually administered locally, intraperitoneally, or even intratumorally. They are tested in urinary bladder cancer (NCT00003167), ovarian (NCT00964756), breast (NCT01703754), prostate (NCT01931046), or pancreatic carcinoma (NCT02705196). Adeno-associated viruses are tested in non-cancer diseases to deliver genes for the experimental treatment of hemophilia B (coagulation factor IX; NCT01620801), lipoprotein lipase deficiency (NCT00891306), Pompe disease ( $\alpha$-glucosidase; NCT00976352), or genetic retinopathies (NCT01482195). In gastric cancer, AAV is used to transfect patient's dendritic cells, which are later mixed with his $\mathrm{T}$ lymphocytes to produce specific cytotoxic $\mathrm{T}$ lymphocytes injected i.v. back to the patient (NCT02496273). IONPs are investigated in various applications in biomedicine, above all in diagnostics and tissue imaging (e.g., NCT00147238, NCT01895829). Ferumoxyde, superparamagnetic iron oxide, has already been used in clinical practice in the United States for the treatment iron-deficiency anemia in patients with chronic kidney disease. Finally, PEI particles for delivering gene therapy are utilized in the clinical trials phase I and II of pancreatic ductal adenocarcinoma (NCT01274455), hepatocellular carcinoma (NCT00825474) and urinary bladder carcinoma (NCT00595088, NCT01274455, NCT00393809).

\section{FUTURE PERSPECTIVES}

In addition to animal models and techniques described in this review, there are also novel and promising approaches to target miRNAs under development. Very intriguing strategy present small-molecule inhibitors that target specific miRNAs (SMIRs, e.g., diazobenzene inhibiting miR-21) that usually interfere with miRNA biogenesis and maturation (Wen et al., 2015). SMIRs constitutes a reasonable and evidence based strategy with strong potential and chance for success. The progress of screening techniques and computational stimulation may address bright future in this field. CRISPR/Cas 9 technology is another emerging technique to be used in miRNA targeting therapy. For instance, construction of sequence specific CRISPR/Cas9 based miRNA inhibitor was reported to downregulate miR-17-92 cluster and miR21, two canonical oncogenic miRNAs in cancer (Ho et al., 2015; Narayanan et al., 2016). Since single miRNA has the potential of regulating thousand genes, long non-coding RNA (lncRNA) that is capable of binding multiple miRNAs could consequently impact the expression of thousands of genes. In light of this potentially fundamental biological role, all the lncRNAs that act as endogenous miRNA sponges presents another promising strategy to target miRNAs in cancer. Finally, it can also be envisioned that blocking production, transportation and release of exosome miRNAs may have beneficial effects in controlling cancer development, and this may be achieved by targeting other non-cancerous cells such as the inflammatory cells in the cancer microenvironment.

\section{CONCLUSIONS}

MiRNA-based therapies as a new class of targeted therapy are heading toward from bench to the bedside. It is now generally accepted and many times proved that influencing pathologically changed intracellular levels of miRNAs change oncogenic phenotype of cancer cells in vitro and in vivo. However, as there is no ideal animal model of a human pathology, the translational potential of most studies is somehow limited. In the studies selected for this review, change of a specific miRNA was followed by significant diminishing of tumor size or volume in vivo. The subcutaneous tumor model used in the bulk of the studies clearly do not respond with microenvironment of the normal tumor cells, and also the necessary immunodeficiency of experimental animals do not correspond with immune status of an average 
oncology patient, nevertheless, the results of animal studies are promising.

Serious obstacles still lie in the way to the clinical practice. The main issue is efficient delivery of miRNA-mimics, precursors, expression vectors, or inhibitors. Other important difficulty is an assessment of a proper dose sufficient for anticipated intracellular effects, but lacking or possessing acceptable adverse effects relating to immunostimulation, blood coagulation, or toxicities that account for the specific delivery systems. We also see the importance of nonrodent models in the development of new drugs, as shown on the immunostimulation triggered by oligonucleotides which is significantly different in nature in rodents and primates.

Several miRNAs and delivery system are now tested in clinical trials. Most of them are in phase I or II. Together with more information obtained from preclinical experiments, the results could move us forward on the way to a new approach in targeted therapy-drugs that aim on epigenetic mechanisms of pathophysiological processes.

\section{REFERENCES}

Adams, B. D., Parsons, C., and Slack, F. J. (2015). The tumor-suppressive and potential therapeutic functions of miR-34a in epithelial carcinomas. Expert Opin. Ther. Targets 20, 737-753. doi: 10.1517/14728222.2016.1114102

Akinc, A., Thomas, M., Klibanov, A. M., and Langer, R. (2005). Exploring polyethylenimine-mediated DNA transfection and the proton sponge hypothesis. J. Gene Med. 7, 657-663. doi: 10.1002/jgm.696

Aslam, M. I., Patel, M., Singh, B., Jameson, J. S., and Pringle, J. H. (2012). MicroRNA manipulation in colorectal cancer cells: from laboratory to clinical application. J. Transl. Med. 10:128. doi: 10.1186/1479-5876-10-128

Axtell, M. J., Westholm, J. O., and Lai, E. C. (2011). Vive la différence: biogenesis and evolution of microRNAs in plants and animals. Genome Biol. 12:221. doi: 10.1186/gb-2011-12-4-221

Bader, A. G., Brown, D., and Winkler, M. (2010). The promise of MicroRNA replacement therapy. Cancer Res. 70, 7027-7030. doi: 10.1158/0008-5472.CAN10-2010

Bao, Y., Chen, Z., Guo, Y., Feng, Y., Li, Z., Han, W., et al. (2014). Tumor suppressor MicroRNA-27a in colorectal carcinogenesis and progression by targeting SGPP1 and Smad2. PLOS ONE 9:e105991. doi: 10.1371/journal.pone.01 05991

Beyerle, A., Braun, A., Merkel, O., Koch, F., Kissel, T., and Stoeger, T. (2011). Comparative in vivo study of poly (ethylene imine)/siRNA complexes for pulmonary delivery in mice. J. Control Release Off. J. Control Release Soc. 151, 51-56. doi: 10.1016/j.jconrel.2010.12.017

Bofill-De Ros, X., Villanueva, E., and Fillat, C. (2015). Late-phase miRNAcontrolled oncolytic adenovirus for selective killing of cancer cells. Oncotarget 6, 6179-6190. doi: 10.18632/oncotarget.3350

Bonnet, M.-E., Erbacher, P., and Bolcato-Bellemin, A.-L. (2008). Systemic delivery of DNA or siRNA mediated by linear polyethylenimine (L-PEI) does not induce an inflammatory response. Pharm. Res. 25, 2972-2982. doi: 10.1007/s11095008-9693-1

Braasch, D. A., and Corey, D. R. (2001). Locked nucleic acid (LNA): fine-tuning the recognition of DNA and RNA. Chem. Biol. 8, 1-7. doi: 10.1016/S10745521(00)00058-2

Broderick, J. A., and Zamore, P. D. (2011). MicroRNA therapeutics. Gene Ther. 18, 1104-1110. doi: 10.1038/gt.2011.50

Calin, G. A., and Croce, C. M. (2006). MicroRNA signatures in human cancers. Nat. Rev. Cancer 6, 857-866. doi: 10.1038/nrc1997

\section{AUTHOR CONTRIBUTIONS}

JM did the literature search and wrote the text, JM and OS made the figures, $\mathrm{RD}$ and $\mathrm{OS}$ advised on the concept of the review and lately rearranged, corrected and critically revised the text.

\section{FUNDING}

This work was supported by the grant GA16-18257S of The Grant Agency of Czech Republic, by the internal Masaryk University Faculty of Medicine grants MUNI/A/1284/2015 and MUNI/11/InGA09/2014, by the Ministry of Education, Youth and Sports of the Czech Republic under the project CEITEC 2020 (LQ1601) and by the Czech Ministry of Health under the project MZ CR - RVO (MOU, 00209805).

\section{ACKNOWLEDGMENTS}

The authors gratefully thank for the funding. We apologized to the many authors whose work could not be quoted due to lack of space.

Chang, Y., Liu, C., Yang, J., Liu, G., Feng, F., Tang, J., et al. (2013). miR-20a triggers metastasis of gallbladder carcinoma. J. Hepatol. 59, 518-527. doi: 10.1016/j.jhep.2013.04.034

Chen, L., Lü, M.-H., Zhang, D., Hao, N.-B., Fan, Y.-H., Wu, Y.-Y., et al. (2014). miR-1207-5p and miR-1266 suppress gastric cancer growth and invasion by targeting telomerase reverse transcriptase. Cell Death Dis. 5:e1034. doi: $10.1038 /$ cddis. 2013.553

Chen, Y., Gao, D.-Y., and Huang, L. (2015). In vivo delivery of miRNAs for cancer therapy: challenges and strategies. Adv. Drug Deliv. Rev. 81, 128-141. doi: 10.1016/j.addr.2014.05.009

Cheng, C. J., Saltzman, W. M., and Slack, F. J. (2013). Canonical and non-canonical barriers facing antimir cancer therapeutics. Curr. Med. Chem. 20, 3582-3593. doi: 10.2174/0929867311320290004

Chollet, P., Favrot, M. C., Hurbin, A., and Coll, J.-L. (2002). Side-effects of a systemic injection of linear polyethylenimine-DNA complexes. J. Gene Med. 4, 84-91. doi: 10.1002/jgm.237

Chowdhury, E. H., Maruyama, A., Kano, A., Nagaoka, M., Kotaka, M., Hirose, S., et al. (2006). pH-sensing nano-crystals of carbonate apatite: effects on intracellular delivery and release of DNA for efficient expression into mammalian cells. Gene 376, 87-94. doi: 10.1016/j.gene.2006.02.028

Cong, N., Du, P., Zhang, A., Shen, F., Su, J., Pu, P., et al. (2013). Downregulated microRNA-200a promotes EMT and tumor growth through the Wnt/betacatenin pathway by targeting the E-cadherin repressors ZEB1/ZEB2 in gastric adenocarcinoma. Oncol. Rep. 29, 1579-1587. doi: 10.3892/or.2013.2267

Crooke, S. T. (2007). Antisense Drug Technology: Principles, Strategies, and Applications, 2nd Edn. Boca Raton, FL: CRC Press.

Dong, Y., Zhao, J., Wu, C.-W., Zhang, L., Liu, X., Kang, W., et al. (2013). Tumor suppressor functions of miR-133a in colorectal cancer. Mol. Cancer Res. 11, 1051-1060. doi: 10.1158/1541-7786.MCR-13-0061

Esquela-Kerscher, A., and Slack, F. J. (2006). Oncomirs - microRNAs with a role in cancer. Nat. Rev. Cancer 6, 259-269. doi: 10.1038/nrc1840

Fischer, D., Bieber, T., Li, Y., Elsässer, H. P., and Kissel, T. (1999). A novel non-viral vector for DNA delivery based on low molecular weight, branched polyethylenimine: effect of molecular weight on transfection efficiency and cytotoxicity. Pharm. Res. 16, 1273-1279. doi: 10.1023/A:1014861900478

Frampton, A. E., Castellano, L., Colombo, T., Giovannetti, E., Krell, J., Jacob, J., et al. (2011). MicroRNAs cooperatively inhibit a network of tumor suppressor genes to promote pancreatic tumor growth and progression. Gastroenterology 146, 268.e18-277.e18. doi: 10.1053/j.gastro.2013.10.010 
Garzon, R., Fabbri, M., Cimmino, A., Calin, G. A., and Croce, C. M. (2006). MicroRNA expression and function in cancer. Trends Mol. Med. 12, 580-587. doi: 10.1016/j.molmed.2006.10.006

Geng, L., Zhu, B., Dai, B.-H., Sui, C.-J., Xu, F., Kan, T., et al. (2011). A let7/Fas double-negative feedback loop regulates human colon carcinoma cells sensitivity to Fas-related apoptosis. Biochem. Biophys. Res. Commun. 408, 494-499. doi: 10.1016/j.bbrc.2011.04.074

Glover, J. M., Leeds, J. M., Mant, T. G. K., Amin, D., Kisner, D. L., Zuckerman, J. E., et al. (1997). Phase I safety and pharmacokinetic profile of an intercellular adhesion molecule-1 antisense oligodeoxynucleotide (ISIS 2302). J. Pharmacol. Exp. Ther. 282, 1173-1180.

Grimm, D., Streetz, K. L., Jopling, C. L., Storm, T. A., Pandey, K., Davis, C. R., et al. (2006). Fatality in mice due to oversaturation of cellular microRNA/short hairpin RNA pathways. Nature 441, 537-541. doi: 10.1038/nature04791

Gu, W., Xu, Y., Xie, X., Wang, T., Ko, J.-H., and Zhou, T. (2014). The role of RNA structure at $5^{\prime}$ untranslated region in microRNA-mediated gene regulation. RNA 20, 1369-1375. doi: 10.1261/rna.044792.114

Hanahan, D., and Weinberg, R. A. (2011). Hallmarks of cancer: the next generation. Cell 144, 646-674. doi: 10.1016/j.cell.2011.02.013

Hanini, A., Schmitt, A., Kacem, K., Chau, F., Ammar, S., and Gavard, J. (2011). Evaluation of iron oxide nanoparticle biocompatibility. Int. J. Nanomed. 6, 787-794. doi: 10.2147/IJN.S17574

Hao, Z., Fan, W., Hao, J., Wu, X., Zeng, G. Q., Zhang, L. J., et al. (2016). Efficient delivery of micro RNA to bone-metastatic prostate tumors by using aptamerconjugated atelocollagen in vitro and in vivo. Drug Deliv. 23, 874-881. doi: 10.3109/10717544.2014.920059

He, X., Dong, Y., Wu, C. W., Zhao, Z., Ng, S. S. M., Chan, F. K. L., et al. (2012). MicroRNA-218 inhibits cell cycle progression and promotes apoptosis in colon cancer by downregulating BMI1 polycomb ring finger oncogene. Mol. Med. 18, 1491-1498. doi: 10.2119/molmed.2012.00304

Henry, S. P., Beattie, G., Yeh, G., Chappel, A., Giclas, P., Mortari, A., et al. (2002). Complement activation is responsible for acute toxicities in rhesus monkeys treated with a phosphorothioate oligodeoxynucleotide. Int. Immunopharmacol. 2, 1657-1666. doi: 10.1016/S1567-5769(02)00142-X

Henry, S. P., Bolte, H., Auletta, C., and Kornbrust, D. J. (1997). Evaluation of the toxicity of ISIS 2302, a phosphorothioate oligonucleotide, in a four-week study in cynomolgus monkeys. Toxicology 120, 145-155. doi: 10.1016/S0300483X(97)03661-5

Hiraki, M., Nishimura, J., Takahashi, H., Wu, X., Takahashi, Y., Miyo, M., et al. (2015). Concurrent targeting of KRAS and AKT by MiR-4689 is a novel treatment against mutant KRAS colorectal cancer. Mol. Ther. Nucleic Acids 4:e231. doi: 10.1038/mtna.2015.5

Höbel, S., and Aigner, A. (2013). Polyethylenimines for siRNA and miRNA delivery in vivo. Wiley Interdiscip. Rev. Nanomed. Nanobiotechnol. 5, 484-501. doi: 10.1002/wnan. 1228

Ho, T. T., Zhou, N., Huang, J., Koirala, P., Xu, M., Fung, R., et al. (2015). Targeting non-coding RNAs with the CRISPR/Cas9 system in human cell lines. Nucleic Acids Res. 43:e17. doi: 10.1093/nar/gku1198

Hogg, D. R., and Harries, L. W. (2014). Human genetic variation and its effect on miRNA biogenesis, activity and function. Biochem. Soc. Trans. 42, 1184-1189. doi: 10.1042/BST20140055

Hossain, S., Stanislaus, A., Chua, M. J., Tada, S., Tagawa, Y., Chowdhury, E. H., et al. (2010). Carbonate apatite-facilitated intracellularly delivered siRNA for efficient knockdown of functional genes. J. Control Release Off. J. Control Release Soc. 147, 101-108. doi: 10.1016/j.jconrel.2010.06.024

Hu, Q. L., Jiang, Q. Y., Jin, X., Shen, J., Wang, K., Li, Y. B., et al. (2013). Cationic microRNA-delivering nanovectors with bifunctional peptides for efficient treatment of PANC-1 xenograft model. Biomaterials 34, 2265-2276. doi: 10.1016/j.biomaterials.2012.12.016

Hwang, H.-W., Wentzel, E. A., and Mendell, J. T. (2007). A hexanucleotide element directs microRNA nuclear import. Science 315, 97-100. doi: 10.1126/science. 1136235

Ibrahim, A. F., Weirauch, U., Thomas, M., Grünweller, A., Hartmann, R. K., and Aigner, A. (2011). MicroRNA replacement therapy for miR-145 and miR-33a is efficacious in a model of colon carcinoma. Cancer Res. 71, 5214-5224. doi: 10.1158/0008-5472.CAN-10-4645

Ishida, T., Ichihara, M., Wang, X., Yamamoto, K., Kimura, J., Majima, E., et al. (2006). Injection of PEGylated liposomes in rats elicits PEG-specific IgM, which is responsible for rapid elimination of a second dose of PEGylated liposomes. J. Control Release Off. J. Control Release Soc. 112, 15-25. doi: 10.1016/j.jconrel.2006.01.005

Jeffries, C. D., Fried, H. M., and Perkins, D. O. (2011). Nuclear and cytoplasmic localization of neural stem cell microRNAs. RNA 17, 675-686. doi: 10.1261/rna.2006511

Jin, H. Y., Gonzalez-Martin, A., Miletic, A. V., Lai, M., Knight, S., Sabouri-Ghomi, M., et al. (2015). Transfection of microRNA mimics should be used with caution. Front. Genet. 6:340. doi: 10.3389/fgene.2015.00340

Ju, C., Mo, R., Xue, J., Zhang, L., Zhao, Z., Xue, L., et al. (2014). Sequential intraintercellular nanoparticle delivery system for deep tumor penetration. Angew. Chem. Int. Ed. 53, 6253-6258. doi: 10.1002/anie.201311227

Kanasty, R. L., Whitehead, K. A., Vegas, A. J., and Anderson, D. G. (2012). Action and reaction: the biological response to siRNA and its delivery vehicles. Mol. Ther. J. Am. Soc. Gene Ther. 20, 513-524. doi: 10.1038/mt.2011.294

Kao, S. C., Fulham, M., Wong, K., Cooper, W., Brahmbhatt, H., MacDiarmid, J., et al. (2015). A significant metabolic and radiological response after a novel targeted MicroRNA-based treatment approach in malignant pleural mesothelioma. Am. J. Respir. Crit. Care Med. 191, 1467-1469. doi: 10.1164/rccm.201503-0461LE

Kasinski, A. L., and Slack, F. J. (2011). Epigenetics and genetics. MicroRNAs en route to the clinic: progress in validating and targeting microRNAs for cancer therapy. Nat. Rev. Cancer 11, 849-864. doi: 10.1038/nrc3166

Keklikoglou, I., Hosaka, K., Bender, C., Bott, A., Koerner, C., Mitra, D., et al. (2015). MicroRNA-206 functions as a pleiotropic modulator of cell proliferation, invasion and lymphangiogenesis in pancreatic adenocarcinoma by targeting ANXA2 and KRAS genes. Oncogene 34, 4867-4878. doi: 10.1038/onc.2014.408

Kievit, F. M., Veiseh, O., Bhattarai, N., Fang, C., Gunn, J. W., Lee, D., et al. (2009). PEI-PEG-chitosan copolymer coated iron oxide nanoparticles for safe gene delivery: synthesis, complexation, and transfection. Adv. Funct. Mater. 19, 2244-2251. doi: 10.1002/adfm.200801844

Kievit, F. M., and Zhang, M. (2011). Surface engineering of iron oxide nanoparticles for targeted cancer therapy. Acc. Chem. Res. 44, 853-862. doi: $10.1021 / \operatorname{ar} 2000277$

Komatsu, K., Shibata, T., Shimada, A., Ideno, H., Nakashima, K., Tabata, Y., et al. (2016). Cationized gelatin hydrogels mixed with plasmid DNA induce stronger and more sustained gene expression than atelocollagen at calvarial bone defects in vivo. J. Biomater. Sci. Polym. Ed. 27, 419-430. doi: 10.1080/09205063.2016.1139486

Krieg, A. M., Yi, A.-K., Matson, S., Waldschmidt, T. J., Bishop, G. A., Teasdale, R., et al. (1995). CpG motifs in bacterial DNA trigger direct B-cell activation. Nature 374, 546-549. doi: 10.1038/374546a0

Kumar, R., Singh, S. K., Koshkin, A. A., Rajwanshi, V. K., Meldgaard, M., and Wengel, J. (1998). The first analogues of LNA (locked nucleic acids): phosphorothioate-LNA and 2'-thio-LNA. Bioorg. Med. Chem. Lett. 8, 2219-2222. doi: 10.1016/S0960-894X(98)00366-7

Lahdaoui, F., Delpu, Y., Vincent, A., Renaud, F., Messager, M., Duchêne, B., et al. (2014). miR-219-1-3p is a negative regulator of the mucin MUC4 expression and is a tumor suppressor in pancreatic cancer. Oncogene 34, 780-788. doi: 10.1038/onc. 2014.11

Lellouche, E., Israel, L. L., Bechor, M., Attal, S., Kurlander, E., Asher, V. A., et al. (2015). MagRET nanoparticles: an iron oxide nanocomposite platform for gene silencing from microRNAs to long noncoding RNAs. Bioconjug. Chem. 26, 1692-1701. doi: 10.1021/acs.bioconjchem.5b00276

Levin, A. A. (1999). A review of the issues in the pharmacokinetics and toxicology of phosphorothioate antisense oligonucleotides. Biochim. Biophys. Acta 1489, 69-84. doi: 10.1016/S0167-4781(99)00140-2

Li, Z. F., Liang, Y. M., Lau, P. N., Shen, W., Wang, D. K., Cheung, W. T., et al. (2013). Dynamic localisation of mature microRNAs in Human nucleoli is influenced by exogenous genetic materials. PLoS ONE 8:e70869. doi: 10.1371/journal.pone.0070869

Maeda, H. (2015). Toward a full understanding of the EPR effect in primary and metastatic tumors as well as issues related to its heterogeneity. Adv. Drug Deliv. Rev. 91, 3-6. doi: 10.1016/j.addr.2015.01.002

Mahmoudi, M., Laurent, S., Shokrgozar, M. A., and Hosseinkhani, M. (2011). Toxicity evaluations of superparamagnetic iron oxide nanoparticles: cell "vision" versus physicochemical properties of nanoparticles. ACS Nano 5, 7263-7276. doi: 10.1021/nn2021088 
Malek, A., Merkel, O., Fink, L., Czubayko, F., Kissel, T., and Aigner, A. (2009). In vivo pharmacokinetics, tissue distribution and underlying mechanisms of various PEI(-PEG)/siRNA complexes. Toxicol. Appl. Pharmacol. 236, 97-108. doi: $10.1016 /$ j.taap.2009.01.014

Mallick, S., and Choi, J. S. (2014). Liposomes: versatile and biocompatible nanovesicles for efficient biomolecules delivery. J. Nanosci. Nanotechnol. 14, 755-765. doi: 10.1166/jnn.2014.9080

Matsumura, Y., and Maeda, H. (1986). A new concept for macromolecular therapeutics in cancer chemotherapy: mechanism of tumoritropic accumulation of proteins and the antitumor agent smancs. Cancer Res. 46(12 Part 1):6387-6392.

Merkel, O. M., Beyerle, A., Beckmann, B. M., Zheng, M., Hartmann, R. K., Stöger, T., et al. (2011). Polymer-related off-target effects in non-viral siRNA delivery. Biomaterials 32, 2388-2398. doi: 10.1016/j.biomaterials.2010.11.081

Mittal, A., Chitkara, D., Behrman, S. W., and Mahato, R. I. (2014). Efficacy of gemcitabine conjugated and miRNA-205 complexed micelles for treatment of advanced pancreatic cancer. Biomaterials 35, 7077-7087. doi: 10.1016/j.biomaterials.2014.04.053

Narayanan, A., Hill-Teran, G., Moro, A., Ristori, E., Kasper, D. M., and Roden, C., et al. (2016). In vivo mutagenesis of miRNA gene families using a scalable multiplexed CRISPR/Cas9 nuclease system. Sci. Rep. 6:32386. doi: $10.1038 /$ srep32386

Nchinda, G., Uberla, K., and Zschörnig, O. (2002). Characterization of cationic lipid DNA transfection complexes differing in susceptability to serum inhibition. BMC Biotechnol. 2:12. doi: 10.1186/1472-6750-2-12

Ochiya, T., Nagahara, S., Sano, A., Itoh, H., and Terada, M. (2001). Biomaterials for gene delivery: atelocollagen-mediated controlled release of molecular medicines. Curr. Gene Ther. 1, 31-52. doi: 10.2174/1566523013348887

Ochiya, T., Takahama, Y., Nagahara, S., Sumita, Y., Hisada, A., Itoh, H., et al. (1999). New delivery system for plasmid DNA in vivo using atelocollagen as a carrier material: the Minipellet. Nat. Med. 5, 707-710. doi: 10.1038/9560

Ott, C. E., Grünhagen, J., Jäger, M., Horbelt, D., Schwill, S., Kallenbach, K., et al. (2011). MicroRNAs differentially expressed in postnatal aortic development downregulate elastin via $3^{\prime}$ UTR and coding-sequence binding sites. PLOS ONE 6:e16250. doi: 10.1371/journal.pone.0016250

Park, C. W., Zeng, Y., Zhang, X., Subramanian, S., and Steer, C. J. (2010). Mature microRNAs identified in highly purified nuclei from HCT116 colon cancer cells. RNA Biol. 7, 606-614. doi: 10.4161/rna.7.5.13215

Pathak, K., Keshri, L., and Shah, M. (2011). Lipid nanocarriers: influence of lipids on product development and pharmacokinetics. Crit. Rev. Ther. Drug Carrier Syst. 28, 357-393. doi: 10.1615/CritRevTherDrugCarrierSyst.v28.i4.20

Pramanik, D., Campbell, N. R., Karikari, C., Chivukula, R., Kent, O. A., Mendell, J. T., et al. (2011). Restitution of tumor suppressor microRNAs using a systemic nanovector inhibits pancreatic cancer growth in mice. Mol. Cancer Ther. 10, 1470-1480. doi: 10.1158/1535-7163.MCT-11-0152

Quinn, L., Finn, S. P., Cuffe, S., and Gray, S. G. (2015). Non-coding RNA repertoires in malignant pleural mesothelioma. Lung Cancer Amst. Neth. 90, 417-426. doi: 10.1016/j.lungcan.2015.11.002

RG-101, (2016). Regulus Therapeutics. Available online at: http://regulusrx.com/ programs/clinical-pipeline/rg-101/

Romero-Cordoba, S. L., Salido-Guadarrama, I., Rodriguez-Dorantes, M., and Hidalgo-Miranda, A. (2014). miRNA biogenesis: biological impact in the development of cancer. Cancer Biol. Ther. 15, 1444-1455. doi: 10.4161/15384047.2014.955442

Ruan, K., Fang, X., and Ouyang, G. (2009). MicroRNAs: novel regulators in the hallmarks of human cancer. Cancer Lett. 285, 116-126. doi: 10.1016/j.canlet.2009.04.031

Seto, A. G. (2010). The road toward microRNA therapeutics. Int. J. Biochem. Cell Biol. 42, 1298-1305. doi: 10.1016/j.biocel.2010.03.003

Sheehan, J. P., and Lan, H.-C. (1998). Phosphorothioate oligonucleotides inhibit the intrinsic tenase complex. Blood 92, 1617-1625.

Sicard, F., Gayral, M., Lulka, H., Buscail, L., and Cordelier, P. (2013). Targeting miR-21 for the therapy of pancreatic cancer. Mol. Ther. 21, 986-994. doi: 10.1038/mt.2013.35

Søkilde, R., Newie, I., Persson, H., Borg, Å., and Rovira, C. (2015). Passenger strand loading in overexpression experiments using microRNA mimics. RNA Biol. 12, 787-791. doi: 10.1080/15476286.2015.1020270
Soriano, A., Jubierre, L., Almazán-Moga, A., Molist, C., Roma, J., de Toledo, J. S., et al. (2013). microRNAs as pharmacological targets in cancer. Pharmacol. Res. 75, 3-14. doi: 10.1016/j.phrs.2013.03.006

Suk, J. S., Xu, Q., Kim, N., Hanes, J., and Ensign, L. M. (2016). PEGylation as a strategy for improving nanoparticle-based drug and gene delivery. Adv. Drug Deliv. Rev. 99(Pt A):28-51. doi: 10.1016/j.addr.2015.09.012

Sun, Y., Shen, S., Liu, X., Tang, H., Wang, Z., Yu, Z., et al. (2014). MiR-429 inhibits cells growth and invasion and regulates EMT-related marker genes by targeting Onecut2 in colorectal carcinoma. Mol. Cell. Biochem. 390, 19-30. doi: 10.1007/s11010-013-1950-x

Sun, Z., Song, X., Li, X., Su, T., Qi, S., Qiao, R., et al. (2014). In vivo multimodality imaging of miRNA-16 iron nanoparticle reversing drug resistance to chemotherapy in a mouse gastric cancer model. Nanoscale 6, 14343-14353. doi: 10.1039/C4NR03003F

Tan, Y., and Huang, L. (2002). Overcoming the inflammatory toxicity of cationic gene vectors. J. Drug Target 10, 153-160. doi: 10.1080/10611860290016757

Tang, R., Li, L., Zhu, D., Hou, D., Cao, T., Gu, H., et al. (2012). Mouse miRNA-709 directly regulates miRNA-15a/16-1 biogenesis at the posttranscriptional level in the nucleus: evidence for a microRNA hierarchy system. Cell Res. 22, 504-515. doi: 10.1038/cr.2011.137

Tréhoux, S., Lahdaoui, F., Delpu, Y., Renaud, F., Leteurtre, E., Torrisani, J., et al. (2015). Micro-RNAs miR-29a and miR-330-5p function as tumor suppressors by targeting the MUC1 mucin in pancreatic cancer cells. Biochim. Biophys. Acta Mol. Cell Res. 1853, 2392-2403. doi: 10.1016/j.bbamcr.2015.05.033

van der Ree, M. H., van der Meer, A. J., van Nuenen, A. C., de Bruijne, J., Ottosen, S., Janssen, H. L., et al. (2016). Miravirsen dosing in chronic hepatitis $\mathrm{C}$ patients results in decreased microRNA-122 levels without affecting other microRNAs in plasma. Aliment. Pharmacol. Ther. 43, 102-113. doi: 10.1111/ apt.13432

van Rooij, E., Purcell, A. L., and Levin, A. A. (2012). Developing microRNA therapeutics. Circ. Res. 110, 496-507. doi: 10.1161/CIRCRESAHA.111.247916

Vidic, S., Markelc, B., Sersa, G., Coer, A., Kamensek, U., Tevz, G., et al. (2010). MicroRNAs targeting mutant K-ras by electrotransfer inhibit human colorectal adenocarcinoma cell growth in vitro and in vivo. Cancer Gene Ther. 17, 409-419. doi: 10.1038/cgt.2009.87

Wang, J., Chen, Y., Chen, B., Ding, J., Xia, G., Gao, C., et al. (2010). Pharmacokinetic parameters and tissue distribution of magnetic $\mathrm{Fe}(3) \mathrm{O}(4)$ nanoparticles in mice. Int. J. Nanomed. 5, 861-866. doi: 10.2147/IJN.S13662

Wang, M., Gu, H., Qian, H., Zhu, W., Zhao, C., Zhang, X., et al. (2013). miR-17$5 \mathrm{p} / 20$ a are important markers for gastric cancer and murine double minute 2 participates in their functional regulation. Eur. J. Cancer 49, 2010-2021. doi: 10.1016/j.ejca.2012.12.017

Wei, Y., Li, L., Wang, D., Zhang, C.-Y., and Zen, K. (2014). Importin 8 regulates the transport of mature microRNAs into the cell nucleus. J. Biol. Chem. 289, 10270-10275. doi: 10.1074/jbc.C113.541417

Wen, D., Danquah, M., Chaudhary, A. K., and Mahato, R. I. (2015). Small molecules targeting microRNA for cancer therapy: promises and obstacles. $J$. Control Release 219, 237-247. doi: 10.1016/j.jconrel.2015.08.011

Wu, J., Lizarzaburu, M. E., Kurth, M. J., Liu, L., Wege, H., Zern, M. A., et al. (2001). Cationic lipid polymerization as a novel approach for constructing new DNA delivery agents. Bioconjug. Chem. 12, 251-257. doi: 10.1021/bc000097e

Wu, X., Yamamoto, H., Nakanishi, H., Yamamoto, Y., Inoue, A., Tei, M., et al. (2015). Innovative delivery of siRNA to solid tumors by super carbonate apatite. PLoS ONE 10:e0116022. doi: 10.1371/journal.pone.0116022

Xie, J., Huang, J., Li, X., Sun, S., and Chen, X. (2009). Iron oxide nanoparticle platform for biomedical applications. Curr. Med. Chem. 16, 1278-1294. doi: 10.2174/092986709787846604

Xue, H., Guo, P., Wen, W.-C., and Wong, H. (2015). Lipid-based nanocarriers for RNA delivery. Curr. Pharm. Des. 21, 3140-3147. doi: $10.2174 / 1381612821666150531164540$

Ye, J., Wu, X., Wu, D., Wu, P., Ni, C., Zhang, Z., et al. (2013). miRNA$27 \mathrm{~b}$ targets vascular endothelial growth factor $\mathrm{c}$ to inhibit tumor progression and angiogenesis in colorectal cancer. PLOS ONE 8:e60687. doi: 10.1371/journal.pone.0060687

Zelphati, O., and Szoka, F. C. (1996). Mechanism of oligonucleotide release from cationic liposomes. Proc. Natl. Acad. Sci. U.S.A. 93, 11493-11498. doi: 10.1073/pnas.93.21.11493 
Zhang, J.-S., Liu, F., and Huang, L. (2005). Implications of pharmacokinetic behavior of lipoplex for its inflammatory toxicity. Adv. Drug Deliv. Rev. 57, 689-698. doi: 10.1016/j.addr.2004.12.004

Zhang, X.-X., McIntosh, T. J., and Grinstaff, M. W. (2012). Functional lipids and lipoplexes for improved gene delivery. Biochimie 94, 42-58. doi: 10.1016/j.biochi.2011.05.005

Zhang, Y., Qu, X., Li, C., Fan, Y., Che, X., Wang, X., et al. (2015). miR103/107 modulates multidrug resistance in human gastric carcinoma by downregulating Cav-1. Tumor Biol. 36, 2277-2285. doi: 10.1007/s13277-0142835-7

Zhang, Y., Wang, Z., and Gemeinhart, R. A. (2013). Progress in microRNA delivery. J. Control Release Off. J. Control Release Soc. 172, 962-974. doi: 10.1016/j.jconrel.2013.09.015

Zhao, W.-G., Yu, S.-N., Lu, Z.-H., Ma, Y.-H., Gu, Y.-M., and Chen, J. (2010). The miR-217 microRNA functions as a potential tumor suppressor in pancreatic ductal adenocarcinoma by targeting KRAS. Carcinogenesis 31, 1726-1733. doi: 10.1093/carcin/ bgq160
Zisoulis, D. G., Kai, Z. S., Chang, R. K., and Pasquinelli, A. E. (2012). Autoregulation of microRNA biogenesis by let-7 and argonaute. Nature 486, 541-544. doi: 10.1038/nature11134

Zou, Y., Li, J., Chen, Z., Li, X., Zheng, S., Yi, D., et al. (2015). miR-29c suppresses pancreatic cancer liver metastasis in an orthotopic implantation model in nude mice and affects survival in pancreatic cancer patients. Carcinogenesis 36, 676-684. doi: 10.1093/carcin/bgv027

Conflict of Interest Statement: The authors declare that the research was conducted in the absence of any commercial or financial relationships that could be construed as a potential conflict of interest.

Copyright (c) 2016 Merhautova, Demlova and Slaby. This is an open-access article distributed under the terms of the Creative Commons Attribution License (CC BY). The use, distribution or reproduction in other forums is permitted, provided the original author(s) or licensor are credited and that the original publication in this journal is cited, in accordance with accepted academic practice. No use, distribution or reproduction is permitted which does not comply with these terms. 